Article

\title{
Turbulence in Wall-Wake Flow Downstream of an Isolated Dunal Bedform
}

\author{
Sankar Sarkar ${ }^{1}$, Sk Zeeshan Ali ${ }^{2}$ and Subhasish Dey ${ }^{2, * \mathbb{D}}$ \\ 1 Physics and Applied Mathematics Unit, Indian Statistical Institute, Kolkata, West Bengal 700108, India; \\ sankar_s@isical.ac.in \\ 2 Department of Civil Engineering, Indian Institute of Technology Kharagpur, West Bengal 721302, India; \\ skzeeshanali@iitkgp.ac.in \\ * Correspondence: sdey@iitkgp.ac.in; Tel.: +91-943-471-3850
}

Received: 1 September 2019; Accepted: 19 September 2019; Published: 22 September 2019

check for updates

\begin{abstract}
This study examines the turbulence in wall-wake flow downstream of an isolated dunal bedform. The streamwise flow velocity and Reynolds shear stress profiles at the upstream and various streamwise distances downstream of the dune were obtained. The results reveal that in the wall-wake flow, the third-order moments change their signs below the dune crest, whereas their signs remain unaltered above the crest. The near-wake flow is featured by sweep events, whereas the far-wake flow is controlled by the ejection events. Downstream of the dune, the turbulent kinetic energy production and dissipation rates, in the near-bed flow zone, are positive. However, they reduce as the vertical distance increases up to the lower-half of the dune height and beyond that, they increase with an increase in vertical distance, attaining their peaks at the crest. The turbulent kinetic energy diffusion and pressure energy diffusion rates, in the near-bed flow zone, are negative, whereas they attain their positive peaks at the crest. The anisotropy invariant maps indicate that the data plots in the wall-wake flow form a looping trend. Below the crest, the turbulence has an affinity to a two-dimensional isotropy, whereas above the crest, the anisotropy tends to reduce to a quasi-three-dimensional isotropy.
\end{abstract}

Keywords: hydraulics; turbulent flow; wall-wake flow; dunal bedform

\section{Introduction}

Turbulent flow over dunal bedforms fascinates researchers. The topic is important not only from the viewpoint of intrinsic scientific reasons, but also owing to its far-reaching applications in engineering. In addition to its practical applications, it allows a significant theoretical understanding of wake flows. Despite impressive advances over the past years, an inclusive picture of the flow and turbulence characteristics over a dunal bedform remains far from complete [1]. The dunes are created by an interaction between the flow and bed sediment particles. Dunes are kind of bedforms that are found when the flow variables, such as flow velocity and bed shear stress over a sediment bed surpass their threshold values.

Over the decades, a large corpus of experimental and numerical studies has been reported to grasp the flow features over dunal bedforms. Researchers studied the velocity field over dunes to acquire an insight into the physical features, including the reattachment point, wake region and internal boundary layer [2,3]. The experimental observations of flow over a series of twoand three-dimensional dunes revealed that the two-dimensional dunes induce stronger turbulence compared to their three-dimensional counterparts [4,5]. However, the flow characteristics over a natural dune were found to be quite different from those over an artificial dune [6]. Best [7] found that over the dune crests, the ejections dominate the instantaneous flow field. 
In a natural streamflow, an isolated dunal bedform acts as a bluff-body, producing wall-wake flow at its downstream. The wake flow downstream of an isolated dunal bedform persists up to a certain stretch until the local wake flow diffuses to and becomes the part of the undisturbed upstream flow. Figure 1 presents a conceptual representation of flow past an isolated dunal bedform in $x z$ plane. Here, $x$ is the streamwise distance measured from a convenient point $O$ and $z$ is the vertical distance from the bed. The dune length $L_{d}$ comprises the stoss-side length $L_{s}$ and the leeside length $L_{l}$ $\left(L_{d}=L_{s}+L_{l}\right)$. The dune height $H_{d}$ is the vertical distance of the dune crest from the bed. Downstream of the dune, a flow reversal takes place, called the near-wake flow. Afterward, the flow is called the far-wake flow. In Figure 1, the lower dashed line denotes the locus of $\bar{u}(z)=0$, whereas the upper dashed line signifies the boundary layer $\left(\bar{u}=\bar{u}_{0}\right)$ in the wall-wake flow. Here, $\bar{u}(\mathrm{z})$ is the time-averaged streamwise flow velocity in the wake flow and $\bar{u}_{0}(z)$ is the time-averaged streamwise flow velocity in the undisturbed upstream flow. In the far downstream of the dunal bedform, the flow achieves the undisturbed upstream state, called the fully recovered open-channel flow.

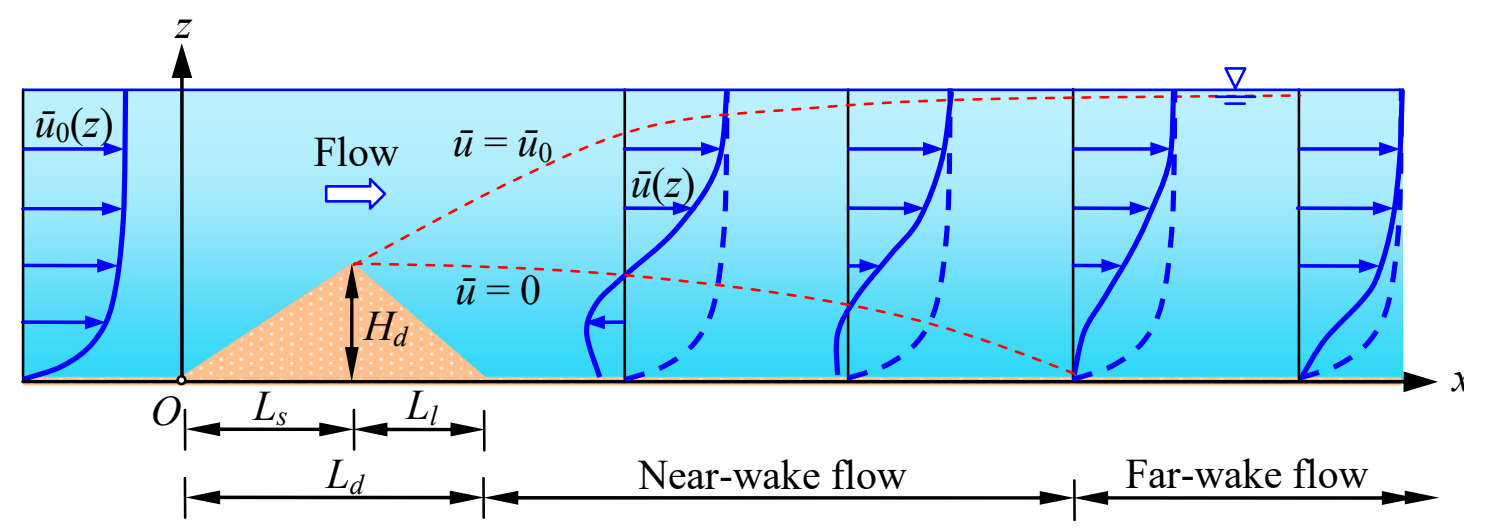

Figure 1. Conceptual sketch of flow over an isolated dunal bedform.

In this context, it is pertinent to mention that for a shear-free flow, Schlichting [8] pioneered the similarity theory of the velocity defect profile in the free-wake flow downstream of a circular cylinder. The wall-wake flow downstream of an isolated dunal bedform in an approach wall-shear flow, being different from a free-wake flow, is rather intricate. The turbulence characteristics and the vortex shedding downstream of bed-mounted bluff-bodies in both near- and far-wake flows were studied by various researchers. Some of these bluff-bodies include plate $[9,10]$, hemisphere [11], sphere [12,13], circular cylinder [14-21] and pebble cluster [22].

It is worth noting that most of the former studies were dedicated to understanding the flow features over a continuous train of dunes. In fact, little is known about the flow and turbulence characteristics over an isolated dunal bedform. This study specifically puts into focus the flow and turbulence characteristics downstream of an isolated two-dimensional dunal bedform over a rough bed in order to advance the present state-of-the-art. In addition to time-averaged streamwise flow velocity, the salient features of turbulence, including the Reynolds shear stress, turbulent bursting, turbulent kinetic energy budget and Reynolds stress anisotropy, are greatly discussed. It may be noted that the preliminary studies of flow and turbulence characteristics downstream of an isolated dunal bedform have been recently presented elsewhere [23,24].

\section{Experimental Design}

Experiments were performed in a re-circulatory flume, having a rectangular cross-section, at the Fluvial Mechanics Laboratory in the Indian Statistical Institute, Kolkata, India. The length, width and height of the flume were $20 \mathrm{~m}, 0.5 \mathrm{~m}$ and $0.5 \mathrm{~m}$, respectively. The inflow discharge, supplied by a centrifugal pump, was measured by an electromagnetic gadget. The transparent sidewalls of the flume provided visual access to the flow. The flume bed, having a streamwise bed slope of $3 \times 10^{-4}$, was 
prepared by gluing uniform gravels of median size $d_{50}=2.49 \mathrm{~mm}$. In the experiments, two types of isolated two-dimensional dunal bedforms, classified as Runs 1 and 2, respectively (Figure 2), were mounted on the flume bed at a distance of $7 \mathrm{~m}$ from the inlet. In Runs 1 and 2, the dune heights $H_{d}$ were $0.09 \mathrm{~m}$ and $0.03 \mathrm{~m}$, whereas the dune lengths $L_{d}$ were $0.4 \mathrm{~m}\left(L_{S}=0.24 \mathrm{~m}\right.$ and $\left.L_{l}=0.16 \mathrm{~m}\right)$ and $0.3 \mathrm{~m}\left(L_{S}=0.24 \mathrm{~m}\right.$ and $\left.L_{l}=0.06 \mathrm{~m}\right)$, respectively. In both the runs, the same approach uniform flow condition was maintained. The approach flow depth $h$ and depth-averaged approach flow velocity $\bar{U}_{0}$ were maintained as $h \approx 0.3 \mathrm{~m}$ and $\bar{U}_{0} \approx 0.44 \mathrm{~m} \mathrm{~s}^{-1}$. The flow depth and the free surface profile were measured by a Vernier point gauge, having a precision of $\pm 0.1 \mathrm{~mm}$. The approach shear velocity $u *$ $\left[=\left(\tau_{0} / \rho\right)^{0.5}\right]$, obtained from the streamwise bed slope, was $0.03 \mathrm{~m} \mathrm{~s}^{-1}$. Here, $\tau_{0}$ is the bed shear stress and $\rho$ is the mass density of fluid. However, the values of $u *$ in both Runs 1 and 2, determined from the Reynolds shear stress profiles, were $0.027 \mathrm{~m} \mathrm{~s}^{-1}$ and $0.025 \mathrm{~m} \mathrm{~s}^{-1}$, respectively. It is worth noting that to find the $u_{*}$ from the Reynolds shear stress profiles, the profiles were extrapolated up to the bed. In both the runs, the flow Reynolds number was 528,000, whereas the flow Froude number was 0.256 (subcritical). The shear Reynolds number $R_{*}\left(=d_{50} u_{*} / v\right.$, where $v$ is the coefficient of kinematic viscosity of fluid) was preserved to be 74.7 (> 70), setting a hydraulically rough flow regime.

(a)

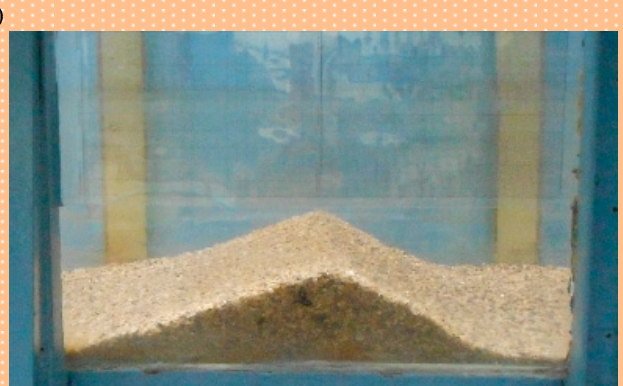

(b)

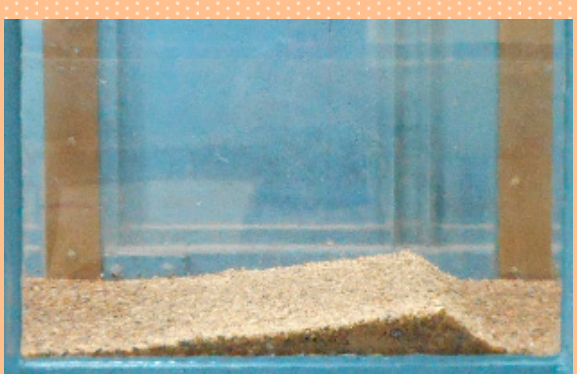

Figure 2. Photographs of isolated dunal bedforms in (a) Run 1 and (b) Run 2. Flow direction is from left to right.

A $5 \mathrm{~cm}$ down-looking Vecrtino probe (acoustic Doppler velocimetry), also called Vectrino plus, was used to capture the instantaneous three-dimensional flow velocity components along the flume centreline at various relative streamwise distances $x / L_{d}=-0.5,-0.25,0,0.1,0.2,0.3,0.4,0.5,0.6,0.7,0.8$, $0.9,1,1.1,1.3,1.7,2.1,2.5$ and 3.3. The Vecrtino system, having a flexible sampling volume of $6 \mathrm{~mm}$ diameter and 1 to $4 \mathrm{~mm}$ height, was operated with $10 \mathrm{MHz}$ acoustic frequency and $100 \mathrm{~Hz}$ sampling rate. The velocity components $(u, v, w)$ correspond to $(x, y, z)$, where $y$ is the spanwise direction. It may be noted that up to the dune crest, the lowest sampling height was set as $1 \mathrm{~mm}$, whereas beyond the crest, it was $2.5 \mathrm{~mm}$. The closest measuring location of the data points was $2 \mathrm{~mm}$. A sampling duration of $300 \mathrm{~s}$ was found to be adequate to obtain the time-independent flow velocity and turbulence quantities. The minimum signal-to-noise ratio was maintained as 18 , whereas the minimum threshold of signal correlation was maintained as $70 \%$. The measured data were filtered whenever required applying the acceleration thresholding method [25]. This method could separate and substitute the unwanted data spikes in two phases. The threshold values of 1 to 1.5 for decontaminating the measured data were ascertained by satisfying Kolmogorov ' $-5 / 3$ ' scaling law in the inertial subrange for the spectral density function $S_{d f}\left(k_{w}\right)$ of streamwise velocity fluctuations $u^{\prime}$. Here, $k_{w}$ is the wavenumber $(=2 \pi f / \bar{u})$ and $f$ is the frequency. Figure $3 \mathrm{a}, \mathrm{b}$ illustrates the data plots of $S_{d f}\left(k_{w}\right)$ for velocity fluctuations $\left(u^{\prime}, v^{\prime}, w^{\prime}\right)$ in $(x, y, z)$ before and after decontaminating the data in Run 1 , respectively, at a relative streamwise distance $x / L_{d}=0.7$ and a relative vertical distance $z / L_{d}=0.13$. The $S_{d f}\left(k_{w}\right)$ curves of decontaminated signals compare well with Kolmogorov ' $-5 / 3$ ' scaling law in the inertial subrange for $k_{w} \geq 30 \mathrm{rad} \mathrm{s}^{-1}$. In addition, it appears that the discrete spectral peaks are prominent for $k_{w}<30 \mathrm{rad} \mathrm{s}^{-1}$. This indicates that the signals corresponding to $k_{w}<30 \mathrm{rad} \mathrm{s}^{-1}$ contained large-scale turbulent structures, while those for $k_{w} \geq 30 \mathrm{rad} \mathrm{s}^{-1}$ confirmed a pure turbulence. Therefore, a high-pass filter with a cut-off wavenumber of $30 \mathrm{rad} \mathrm{s}^{-1}$ was used to filter the data. 
(a)

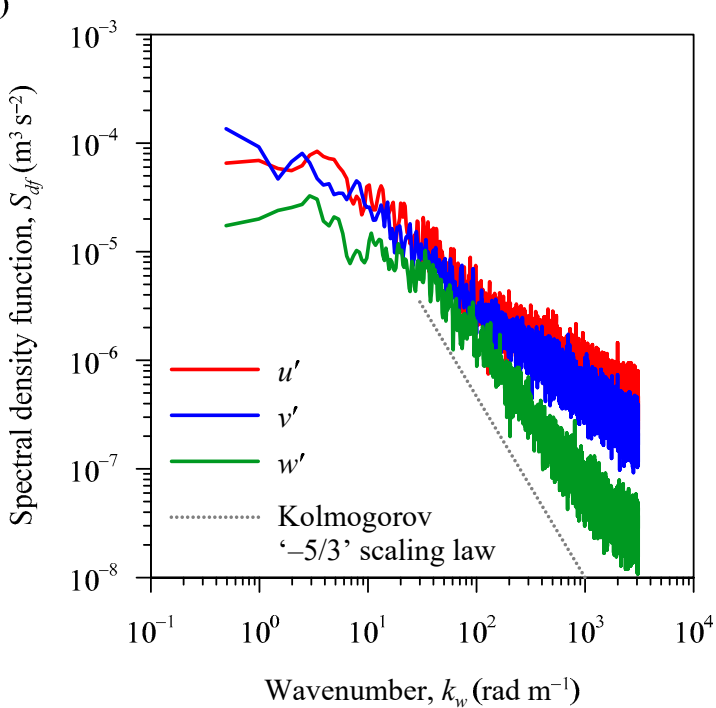

(b)

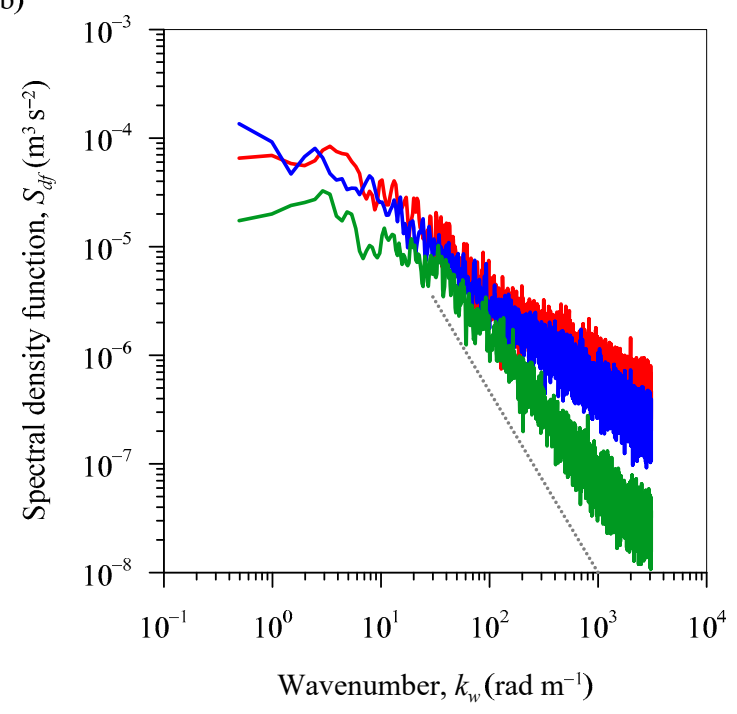

Figure 3. Spectral density function $S_{d f}\left(k_{w}\right)$ versus wavenumber $k_{w}$ (a) before and (b) after decontaminating the data in Run 1 at a relative streamwise distance $x / L_{d}=0.7$ and a relative vertical distance $z / L_{d}=0.13$.

In order to find the uncertainty of Vectrino data, 15 samples were collected at a sampling rate of $100 \mathrm{~Hz}$ for a duration of $300 \mathrm{~s}$ at a vertical distance $z=5 \mathrm{~mm}$. Table 1 summarizes the results of uncertainty estimations of the time-averaged velocity components $(\bar{u}, \bar{v}, \bar{w})$ and the turbulence intensities $\left[\left(\overline{u^{\prime} u^{\prime}}\right)^{0.5},\left(\overline{v^{\prime} v^{\prime}}\right)^{0.5},\left(\overline{w^{\prime} w^{\prime}}\right)^{0.5}\right]$ in $(x, y, z)$ and the Reynolds shear stress $\tau$ per unit mass density of fluid $\left(=-\overline{u^{\prime} w^{\prime}}\right)$. It is pertinent to mention that to avoid bias and random errors, the samplings were done every time after resuming the experiments. The errors for the time-averaged velocity components, turbulence intensities and Reynolds shear stress were within $\pm 4 \%, \pm 7 \%$ and $\pm 8 \%$, respectively. This confirmed the appropriateness of the data sampling with $100 \mathrm{~Hz}$ sampling rate. Further, it was necessary to ascertain the fully-developed undisturbed approach velocity profiles for both the Runs. Figure 4 shows the vertical profiles of nondimensional streamwise flow velocity $\bar{u}^{+}\left(=\bar{u} / u_{*}\right)$ at the upstream of isolated dunal bedforms for both Runs 1 and 2 . The data plots compare well with the classical logarithmic law $\bar{u} / u_{*}=\kappa^{-1} \ln \left(z / d_{50}\right)+8.5$ for a hydraulically rough flow regime. Here, $\kappa$ is the von Kármán constant $(=0.41)$. This confirmed the acceptability of the fully-developed undisturbed approach flow velocity profiles for a hydraulically rough flow regime.

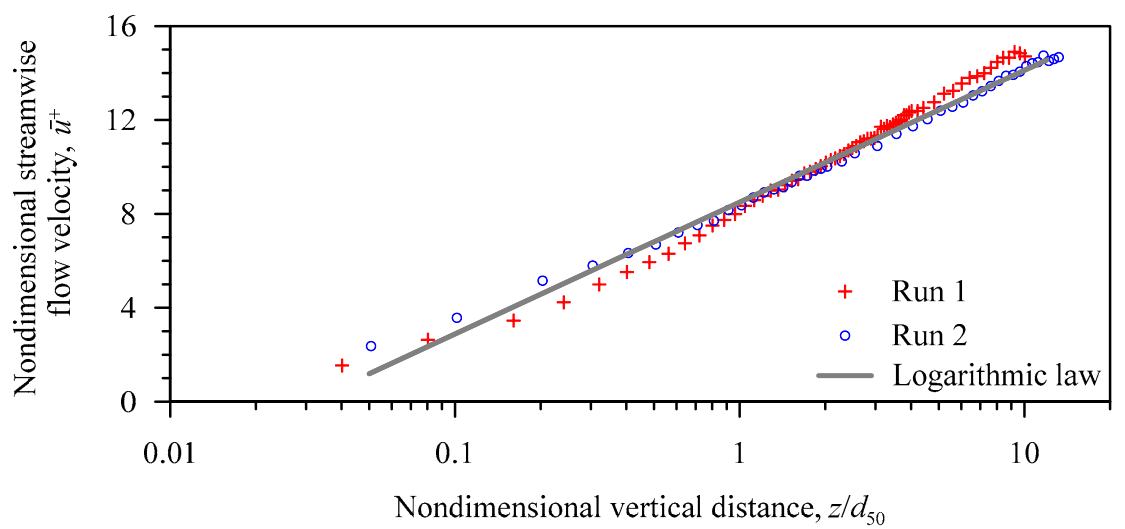

Figure 4. Vertical profiles of nondimensional streamwise flow velocity $\bar{u}^{+}$at the upstream of isolated dunal bedforms for Runs 1 and 2. 
Table 1. Uncertainty estimation for Vectrino.

\begin{tabular}{|c|c|c|c|c|c|c|}
\hline $\bar{U}\left(\mathrm{~m} \mathrm{~s}^{-1}\right)$ & $\bar{v}\left(\mathrm{~m} \mathrm{~s}^{-1}\right)$ & $\bar{w}\left(\mathrm{~m} \mathrm{~s}^{-1}\right)$ & $\begin{array}{l}\left(\overline{\left(\overline{u^{\prime} u^{\prime}}\right)^{0.5}}\right. \\
\left(\mathrm{m} \mathrm{s}^{-1}\right)\end{array}$ & $\begin{array}{l}\left(\overline{\bar{v}^{\prime} v^{\prime}}\right)^{0.5} \\
\left(\mathrm{~m} \mathrm{~s}^{-1}\right)\end{array}$ & $\begin{array}{c}\left(\overline{w^{\prime} w^{\prime}}\right)^{0.5} \\
\left(\mathrm{~m} \mathrm{~s}^{-1}\right)\end{array}$ & $\tau\left(\mathrm{m}^{2} \mathrm{~s}^{-2}\right)$ \\
\hline $\begin{array}{c}2.94 \times 10^{-3 *} \\
\left( \pm 2.93 \times 10^{-2}+\right)\end{array}$ & $\begin{array}{c}2.33 \times 10^{-3} \\
\left( \pm 3.02 \times 10^{-2}\right)\end{array}$ & $\begin{array}{c}1.75 \times 10^{-3} \\
\left( \pm 3.95 \times 10^{-2}\right)\end{array}$ & $\begin{array}{c}2.18 \times 10^{-3} \\
\left( \pm 5.87 \times 10^{-2}\right)\end{array}$ & $\begin{array}{c}1.34 \times 10^{-3} \\
\left( \pm 6.72 \times 10^{-2}\right)\end{array}$ & $\begin{array}{c}1.07 \times 10^{-3} \\
\left( \pm 6.89 \times 10^{-2}\right)\end{array}$ & $\begin{array}{c}4.37 \times 10^{-5} \\
\left( \pm 7.48 \times 10^{-4}\right)\end{array}$ \\
\hline
\end{tabular}

\section{Time-Averaged Flow}

\subsection{Streamwise Flow Velocity}

Figure 5 shows the vertical profiles of nondimensional streamwise flow velocity $\bar{u}^{+}$at upstream and various downstream relative streamwise distances $x / L_{d}$ in Runs 1 and 2. Immediate downstream of the dune $\left(x / L_{d}=1\right)$, the wall-shear flow separates from the dune crest, giving rise to a flow reversal owing to negative streamwise flow velocity. The near-wake flow zone extends up to $x / L_{d} \approx 1.7$. As the flow reaches further downstream, the flow reversal disappears. In addition, the streamwise flow velocity, having a velocity defect, starts to recover the undisturbed upstream velocity profile in the far-wake zone $\left(x / L_{d}=2.1\right.$ to 2.5$)$. At $x / L_{d} \approx 3.3$, the velocity profile appears to follow the undisturbed upstream velocity profile. It is also evident that above the relative vertical distance $z / H_{d}=1.5$, the values of $\bar{u}^{+}$remain almost the same irrespective of $x / L_{d}$. However, the extents of the near- and far-wake flow zones in Runs 1 and 2 are different because of the effects of dune dimensions. It is worth mentioning that in wall-wake flows downstream of a sphere and a horizontal cylinder, the velocity profiles appear to follow their corresponding undisturbed upstream velocity profile at streamwise distances equaling roughly 8.5 and 7 times the diameter of sphere and cylinder, respectively [12,21].

(a)

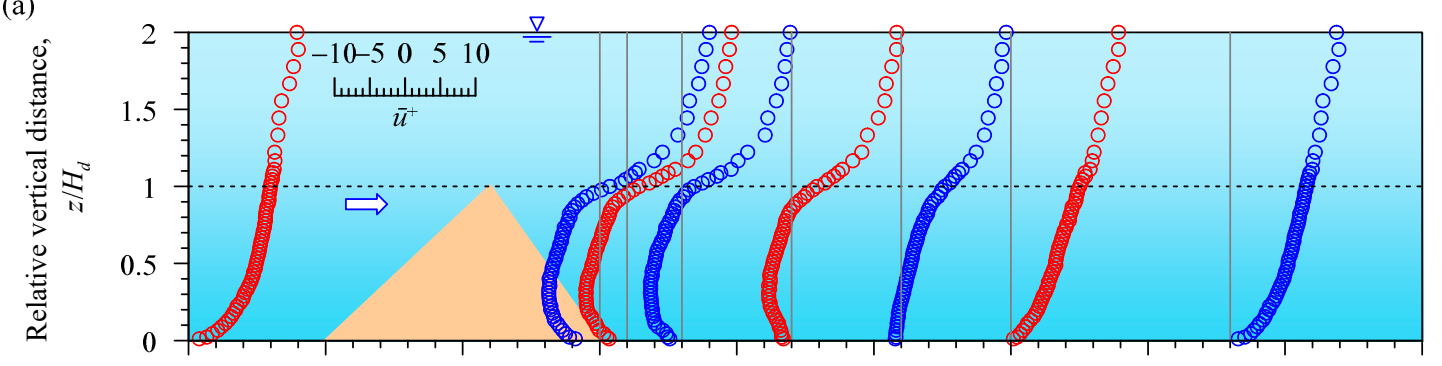

(b)

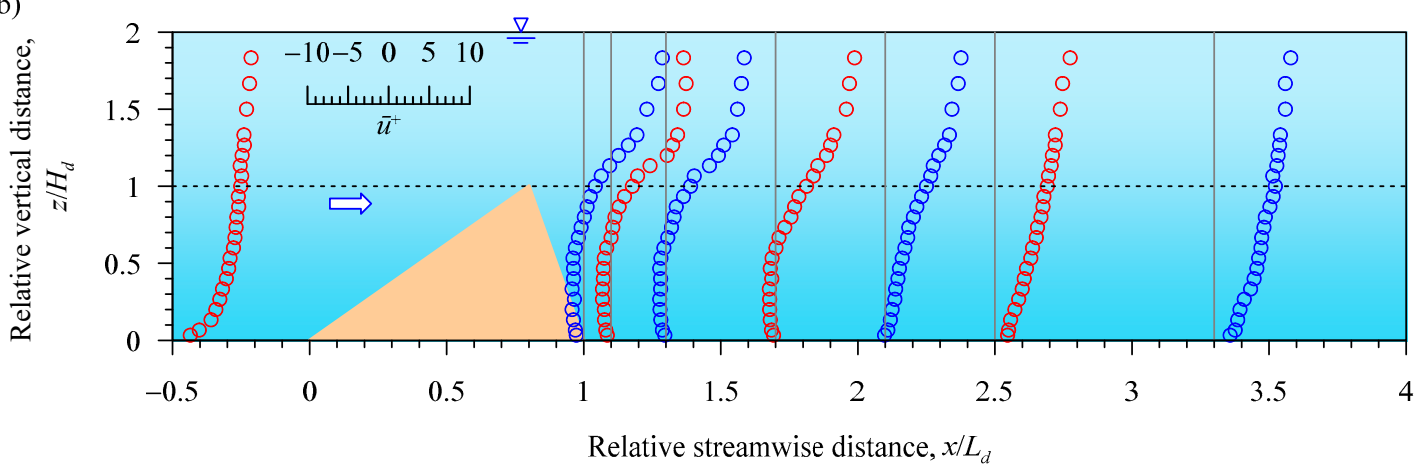

Figure 5. Vertical profiles of nondimensional streamwise flow velocity $\bar{u}^{+}$at the upstream and various downstream relative streamwise distances $x / L_{d}$ of isolated dunal bedforms for (a) Run 1 and (b) Run 2.

\subsection{Reynolds Shear Stress}

Figure 6 presents the vertical profiles of nondimensional Reynolds shear stress $\tau^{+}\left(=\tau / u_{*}^{2}\right)$ at the upstream and various downstream relative streamwise distances $x / L_{d}$ in Runs 1 and 2. Upstream of the dune $\left(x / L_{d}=-0.5\right)$, the $\tau^{+}$profile follows a linear law. The $\tau^{+}$is approximately unity at the 
relative vertical distance $z / H_{d}=0$ and then, it reduces with an increase in relative vertical distance to become zero at the free surface (if the profiles would be extended up to the free surface). Immediate downstream of the dune $\left(x / L_{d}=1\right)$, the $\tau^{+}$is negative in the near-bed flow zone. Thereafter, it increases with an increase in $z / H_{d}$, attaining a positive peak at the dune crest $\left(z / H_{d}=1\right)$. Above the crest, the $\tau^{+}$decreases with an increase in $z / H_{d}$ and attains almost similar pattern to the upstream profile for $z / H_{d}>1.5$. It appears that for a given $z / H_{d}$, the $\tau^{+}$decreases with an increase in $x / L_{d}$. In particular, at $x / L_{d} \approx 3.3$, the $\tau^{+}$profile becomes almost similar to the upstream profile at $x / L_{d}=-0.5$. It may be noted that for $z / H_{d}>1.75$, the values of $\tau^{+}$at various $x / L_{d}$ are nearly similar. Therefore, it may be concluded that the Reynolds shear stress in the wall-wake flow is influenced by the dune up to a vertical distance of approximately 1.75 times the dune height and a streamwise distance of approximately 2.5 times the dune length.

(a)

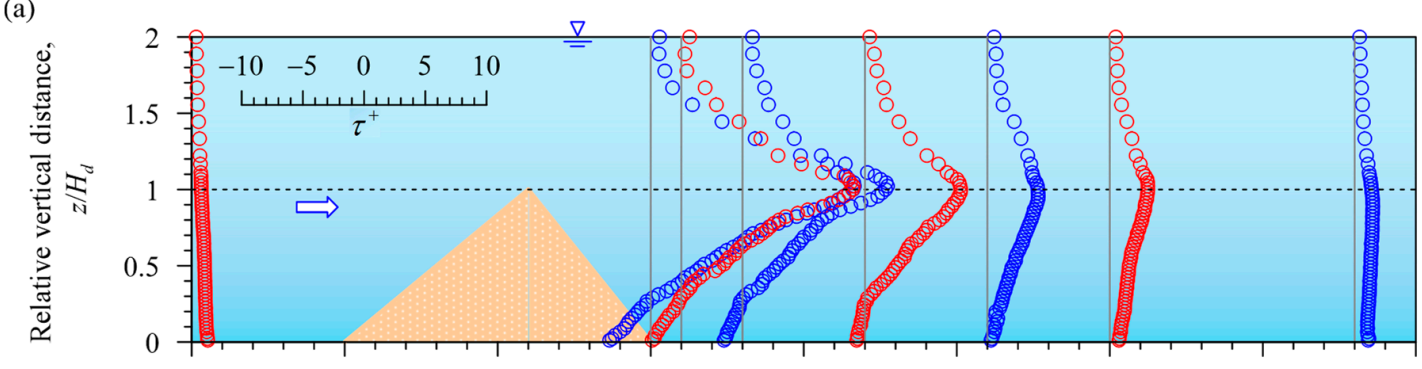

(b)

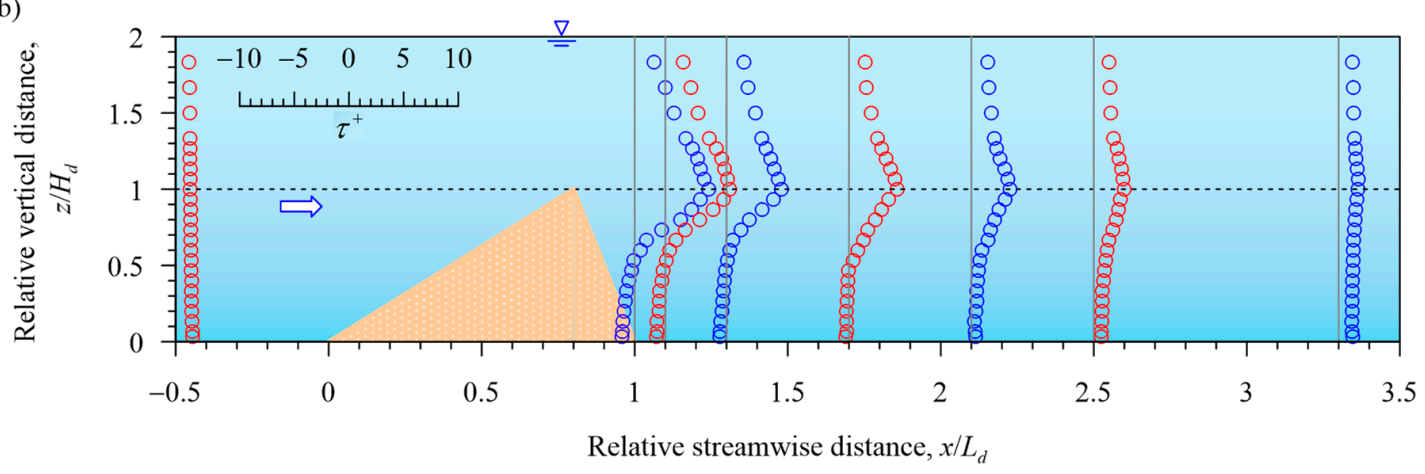

Figure 6. Vertical profiles of nondimensional Reynolds shear stress $\tau^{+}$at the upstream and various downstream relative streamwise distances $x / L_{d}$ of isolated dunal bedforms for (a) Run 1 and (b) Run 2.

\section{Third-Order Moments}

The third-order moments of velocity fluctuations offer relevant probabilistic information about the flux and the advection of Reynolds normal stresses. In addition, they give an indication of the predominance of turbulent bursting events [26]. The third-order moments, in the generalized form in $x z$ plane, is expressed as $m_{j k}=\overline{\widetilde{u}} \widetilde{w}^{k}$, where $\widetilde{u}=u^{\prime} /\left(\overline{u^{\prime} u^{\prime}}\right)^{0.5}, \widetilde{w}=w^{\prime} /\left(\overline{w^{\prime} w^{\prime}}\right)^{0.5}$ and $j+k=3$. Therefore, depending on the values of $j$ and $k$, the third-order moments are given as, $m_{30}=\overline{u^{\prime} u^{\prime} u^{\prime}} /\left(\overline{u^{\prime} u^{\prime}}\right)^{1.5}$, $m_{03}=\overline{w^{\prime} w^{\prime} w^{\prime}} /\left(\overline{w^{\prime} w^{\prime}}\right)^{1.5}, m_{21}=\overline{u^{\prime} u^{\prime} w^{\prime}} /\left[\overline{\left(\overline{u^{\prime} u^{\prime}}\right)} \times\left(\overline{w^{\prime} w^{\prime}}\right)^{0.5}\right]$ and $m_{12}=\overline{u^{\prime} w^{\prime} w^{\prime}} /\left[\left(\overline{u^{\prime} u^{\prime}}\right)^{0.5} \times\left(\overline{w^{\prime} w^{\prime}}\right)\right]$. Here, the $m_{30}$ signifies the skewness of $u^{\prime}$, indicating the streamwise flux of the streamwise Reynolds normal stress $\overline{u^{\prime} u^{\prime}}$. The $m_{03}$ defines the skewness of $w^{\prime}$, suggesting the vertical flux of the vertical Reynolds normal stress $\overline{w^{\prime} w^{\prime}}$. In addition, the $m_{21}$ represents the advection of $\overline{u^{\prime} u^{\prime}}$ in the vertical direction, whereas the $m_{12}$ demonstrates the advection of $\overline{w^{\prime} w^{\prime}}$ in the streamwise direction.

Figure 7 shows the vertical profiles of $m_{30}$ and $m_{03}$ at the upstream and various downstream relative streamwise distances $x / L_{d}$ in Runs 1 and 2. Upstream of the dune $\left(x / L_{d}=-0.5\right)$, the $m_{30}$ and $m_{03}$, in the near-bed flow zone, are negative and positive, respectively. Then, they increase with an increase in relative vertical distance $z / H_{d}$ without changing their signs. Downstream of the dune $\left(x / L_{d}=1\right.$ to 2.1), for a given $x / L_{d}$, the $m_{30}$ and $m_{03}$, in the near-bed flow zone, start with positive and negative values, respectively. Thereafter, they increase slowly with an increase in $z / H_{d}$ until they attain their 
respective positive and negative peaks at $z / H_{d} \approx 0.75$ and 0.5 . As the $z / H_{d}$ increases further, the $m_{30}$ and $m_{03}$ reduce quickly, changing their signs at $z / H_{d}=1$, and for $z / H_{d}>1$, they become independent of $z / H_{d}$. However, these features disappear gradually with an increase in $x / L_{d}$. It may be noted that the $m_{30}$ and $m_{03}$ profiles at $x / L_{d}=3.3$ remain almost similar to those in the upstream.
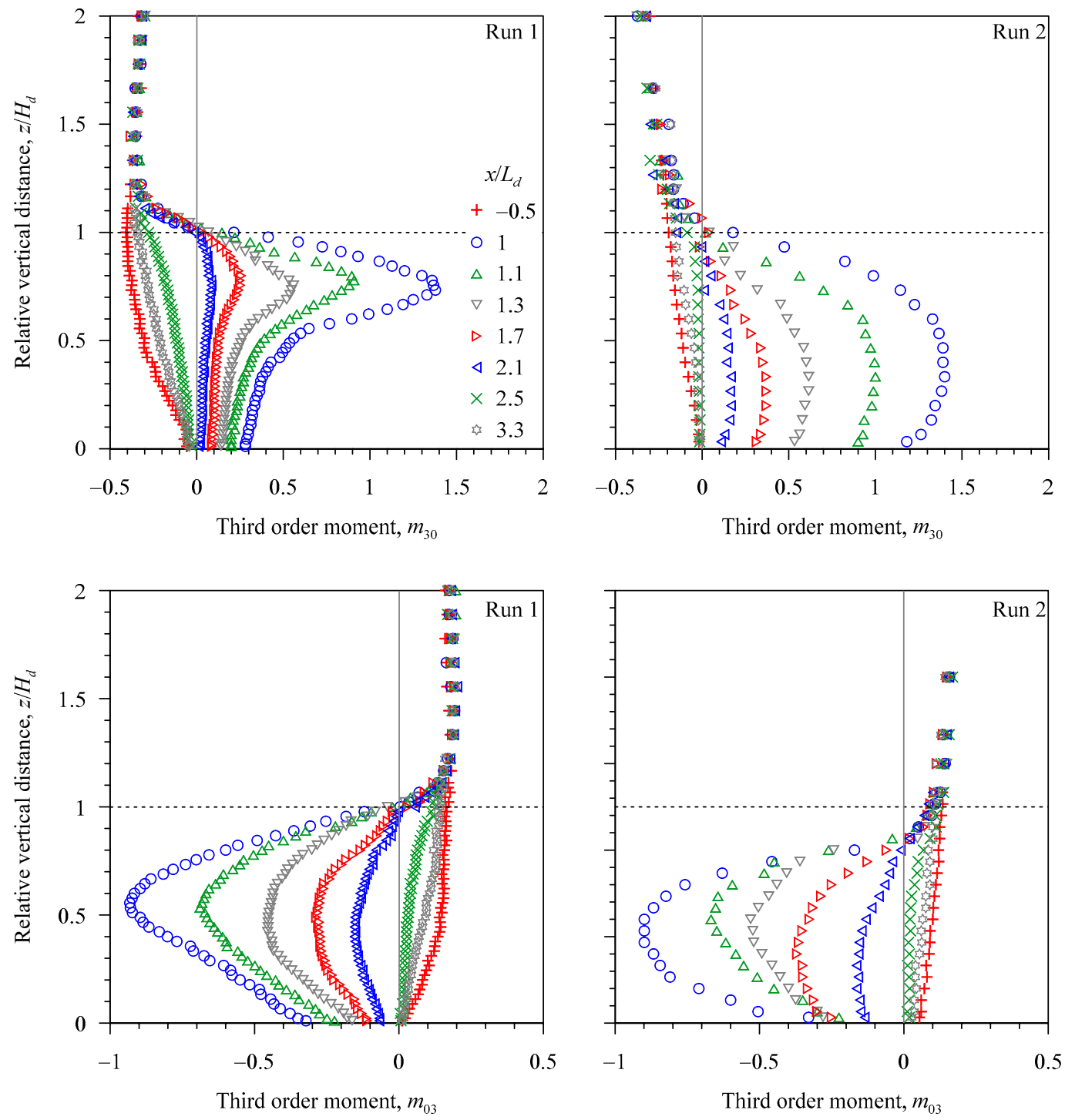

Figure 7. Vertical profiles of third-order moments $m_{30}$ and $m_{03}$ at various relative streamwise distances $x / L_{d}$ in Runs 1 and 2.

Figure 8 depicts the vertical profiles of $m_{21}$ and $m_{12}$ at the upstream and various downstream relative streamwise distances $x / L_{d}$ in Runs 1 and 2. It appears that upstream of the dune $\left(x / L_{d}=-0.5\right)$, the $m_{21}$ and $m_{12}$, in the near-bed flow zone, attain positive and negative values, respectively. Then, they increase with an increase in relative vertical distance $z / H_{d}$ up to a certain height. Subsequently, they reduce with an increase in $z / H_{d}$, becoming independent of $z / H_{d}$ for $z / H_{d}>1.1$. Downstream of the dune ( $x / L_{d}=1$ to 2.1), for a given $x / L_{d}$, the $m_{21}$ and $m_{12}$, in the near-bed flow zone, are negative and positive, respectively. Then, they increase with an increase in $z / H_{d}$ attaining their respective peaks. Afterward, they reduce quickly, changing their signs at the dune crest $\left(z / H_{d}=1\right)$. Thereafter, the $m_{21}$ and $m_{12}$ profiles recover their upstream profiles. Downstream of the dune, an advection of $\overline{u^{\prime} u^{\prime}}$ in the upward direction and that of $\overline{w^{\prime} w^{\prime}}$ in the upstream direction prevail below the crest. In fact, below the crest, there appears a streamwise acceleration, which is linked with the downward flux causing sweeps 
with an advection of $\overline{u^{\prime} u^{\prime}}$ in the downward direction. By contrast, above the crest, the streamwise deceleration is associated with an upward flux producing ejections with an advection of $\overline{u^{\prime} u^{\prime}}$ in the upward direction.
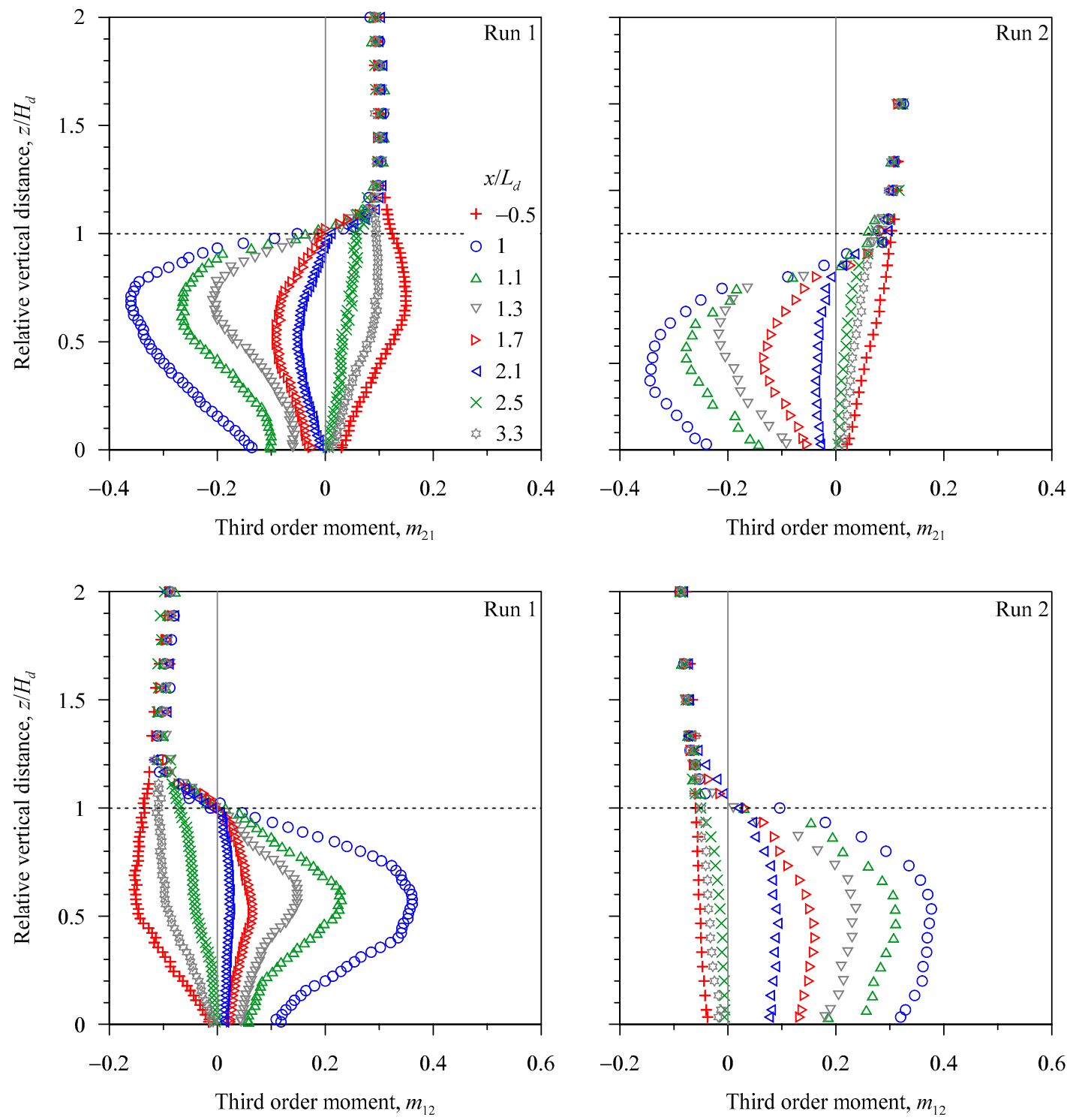

Figure 8. Vertical profiles of third-order moments $m_{21}$ and $m_{12}$ at various relative streamwise distances $x / L_{d}$ in Runs 1 and 2.

\section{Quadrant Analysis}

Lu and Willmarth [27] suggested that the bursting events can be quantified by performing the quadrant analysis of velocity fluctuations $u^{\prime}$ and $w^{\prime}$ on a $u^{\prime} w^{\prime}$ plane. The turbulent bursting includes four events in four distinct quadrants $i=1$ to 4 , such as (i) $Q 1$ events or outward interactions ( $i=1$ and $u^{\prime}, w^{\prime}>0$ ), (ii) $Q 2$ events or ejections ( $i=2$ and $u^{\prime}<0, w^{\prime}>0$ ), (iii) $Q 3$ events or inward interactions ( $i=3$ and $\left.u^{\prime}, w^{\prime}<0\right)$ and (iv) $Q 4$ events or sweeps $\left(i=4\right.$ and $\left.u^{\prime}>0, w^{\prime}<0\right)$. Outside the hole size $H$, the contribution of $\left.\overline{u^{\prime} w^{\prime}}\right|_{i, H}$ from the quadrant $i$ to $\overline{u^{\prime} w^{\prime}}$ is ascertained by averaging the quantity $u^{\prime}(t) w^{\prime}(t) F_{i, H}$ over the sampling duration. Here, $F_{i, H}$ is the detection function, defined as $F_{i, H}=1$ if the pair $\left(u^{\prime}, w^{\prime}\right)$ in the quadrant $i$ satisfies the condition $\left|u^{\prime} w^{\prime}\right| \geq H\left(\overline{u^{\prime} u^{\prime}}\right)^{0.5}\left(\overline{w^{\prime} w^{\prime}}\right)^{0.5}$ and $F_{i, H}=0$ otherwise. The relative fractional contributions $S_{i, H}$ toward the Reynolds shear stress production is expressed as $S_{i, H}=\left.\overline{u^{\prime} w^{\prime}}\right|_{i, H} \overline{u^{\prime} w^{\prime}}$. It turns out that for $H=0$, the sum of $S_{1,0}, S_{2,0}, S_{3,0}$ and $S_{4,0}$ becomes unity. 
Figures 9 and 10 show the vertical profiles of $S_{i, 0}$ at the upstream and various downstream relative streamwise distances $x / L_{d}$ in Runs 1 and 2, respectively. Upstream of the dune $\left(x / L_{d}=-0.5\right)$, the $Q 2$ and $Q 4$ events remain the most and the second-most contributing events, respectively, to the production of Reynolds shear stress. However, the $Q 1$ and $Q 3$ events are trivial across the flow depth. Downstream of the dune $\left(x / L_{d}=1\right.$ to 2.1$)$, all the four events contribute largely below the dune crest with prevailing $Q 4$ events in the form of arrival of high-speed fluid streaks. At $x / L_{d}=2.5$, contributions from the $Q 2$ and $Q 4$ events appear to be nearly equal below the crest. Further downstream $\left(x / L_{d}=3.3\right)$, the $Q 2$ events dominate over $Q 4$ events in the form of arrival of low-speed fluid streaks. It may be noted that above the crest $\left(z / H_{d}>1\right)$, the $Q 2$ events are the most contributing events regardless of $x / L_{d}$.
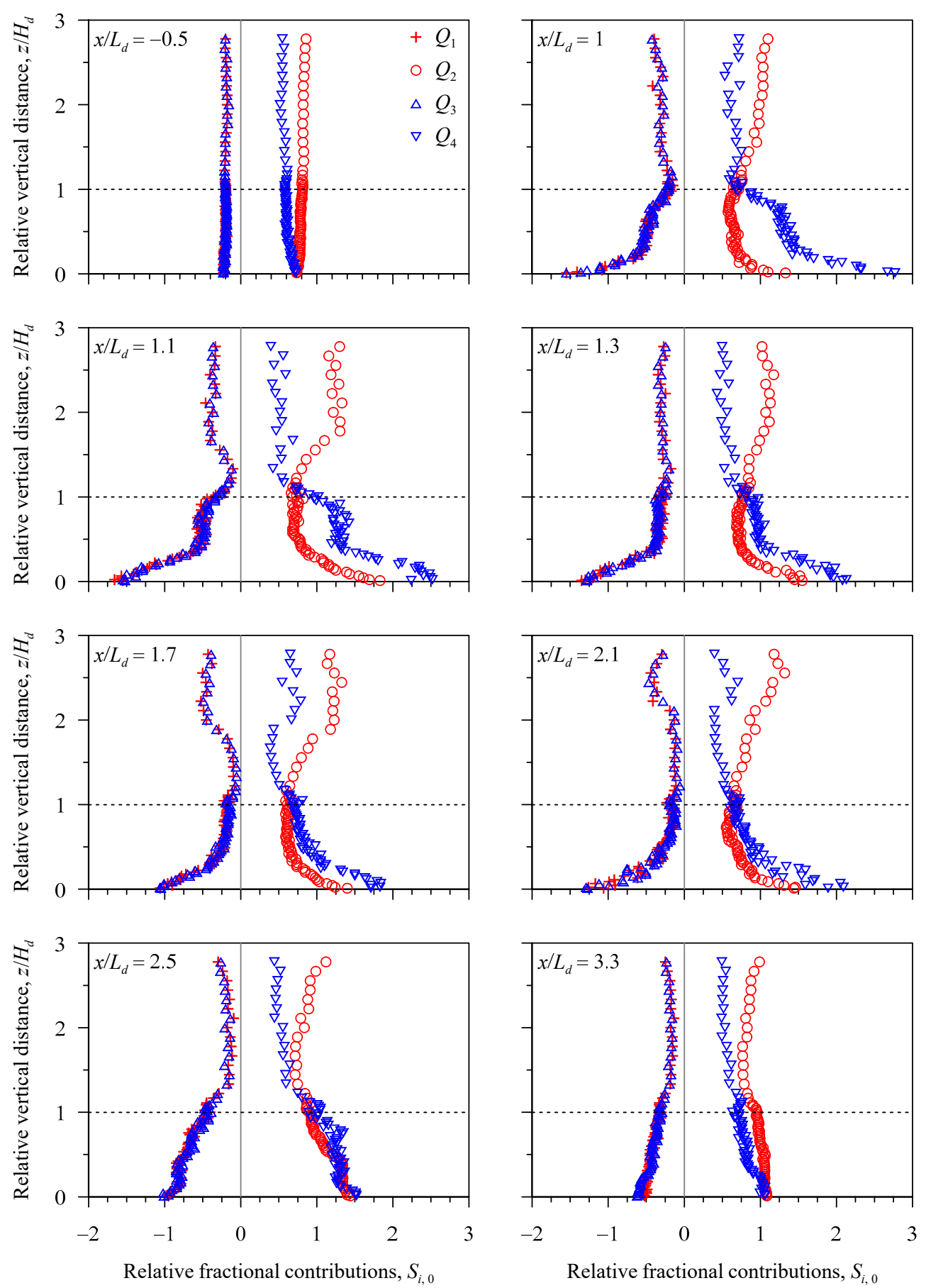

Figure 9. Vertical profiles of relative fractional contributions $S_{i, 0}$ at various relative streamwise distances $x / L_{d}$ in Run 1. 

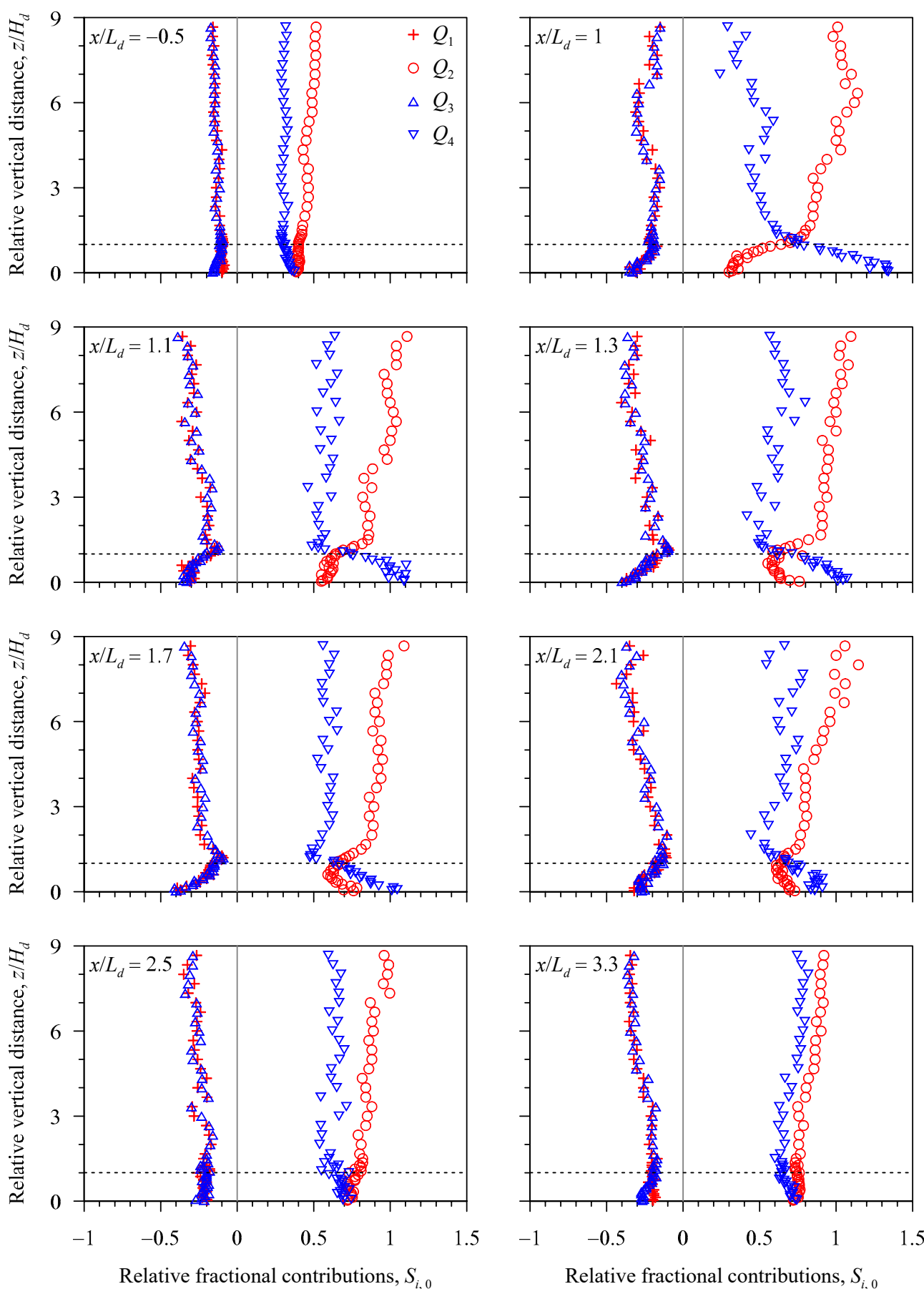

Figure 10. Vertical profiles of relative fractional contributions $S_{i, 0}$ at various relative streamwise distances $x / L_{d}$ in Run 2 .

Figure 11a,b shows the variations of relative fractional contributions $\left|S_{i, H}\right|$ with hole size $H$ in Run 1 for different relative vertical distances $z / H_{d}(=0.05,0.25$ and 0.5$)$ at relative streamwise distances $x / L_{d}=-0.5$ (uninterrupted upstream flow) and 1 (near-wake flow), whereas Figure 12a,b shows those at $x / L_{d}=1.7$ (far-wake flow) and 3.3 (near to fully recovered flow). It appears that upstream of the dune $\left(x / L_{d}=-0.5\right)$, the $Q 1$ and $Q 3$ events for $z / H_{d}=0.05$ contribute minimally to the Reynolds shear stress production as compared to the $Q 2$ and $Q 4$ events. However, for $z / H_{d}=0.05$, the pairs $(Q 1, Q 3)$ and $(Q 2$, $Q 4)$ are equal, indicating that they mutually cancel the dominance of each other. At $x / L_{d}=-0.5$, the $Q 2$ events remain dominant for $z / D=0.25$ and 0.5 . Immediate downstream of the dune $\left(x / L_{d}=1\right)$, the $Q 1$ and $Q 3$ events, for a given $z / H_{d}$, are smaller than $Q 2$ and $Q 4$ events. However, at the downstream, 
the $Q 4$ remain the most dominant events for $z / H_{d}=0.05,0.25$ and 0.5 . At $x / L_{d}=1.7$, these features remain similar to those at $x / L_{d}=1$, but with relatively smaller $Q 4$ events. Far downstream of the dune $\left(x / L_{d}=3.3\right)$, the events, for a given $z / H_{d}$, follow the upstream trend. The contributions from the events are considerable for lower values of $H$. In essence, for $H \geq 12$, all the events are trivial at different streamwise and vertical distances.

(a)
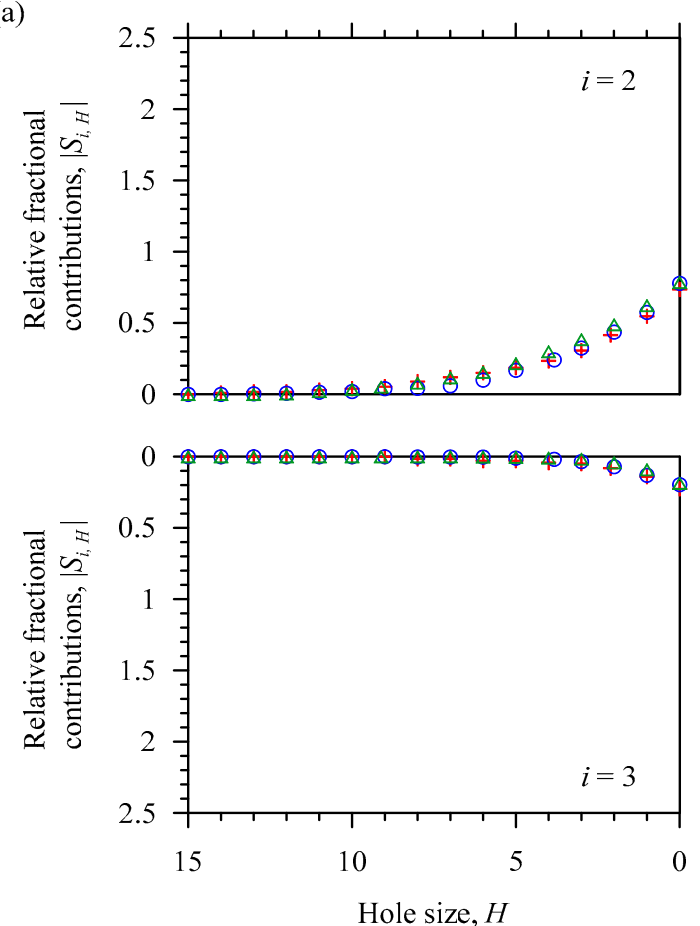

(b)
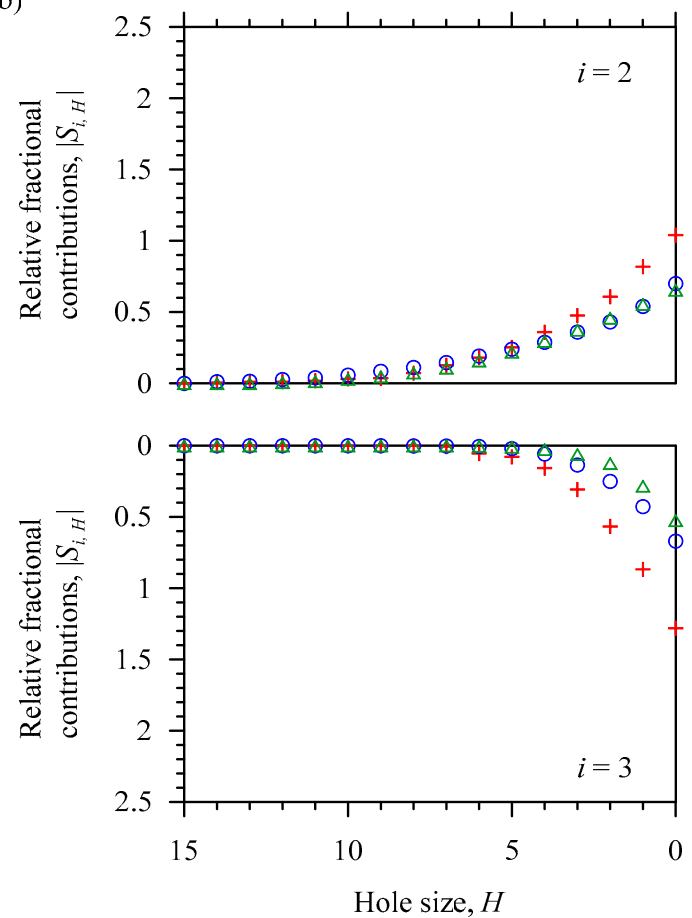
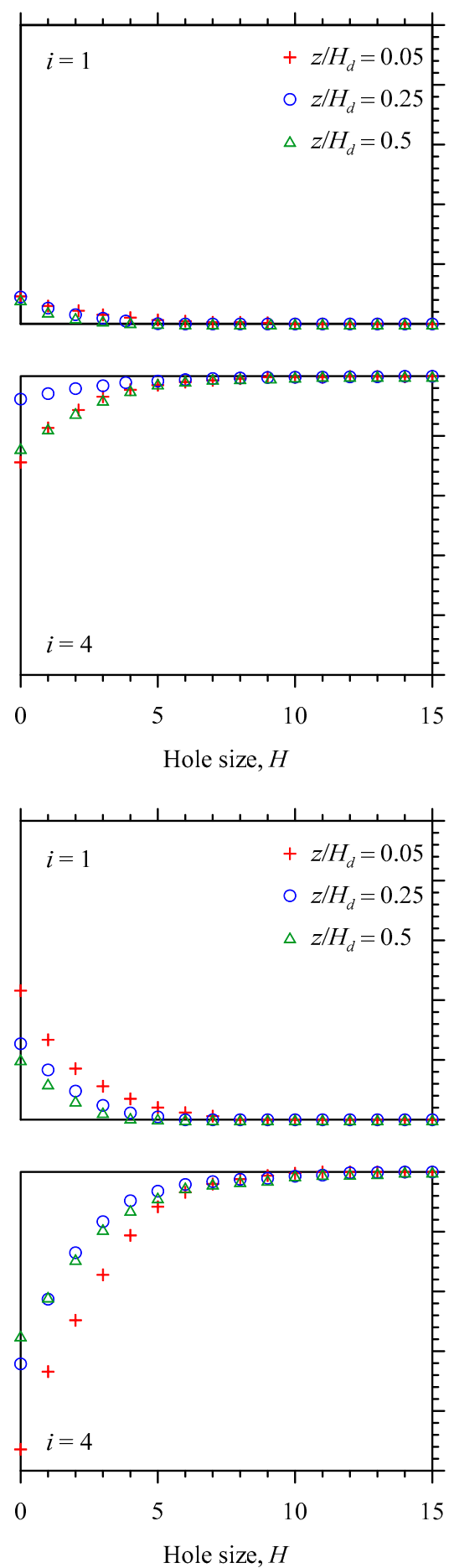

Figure 11. Relative fractional contributions $\left|S_{i, H}\right|$ as a function of hole size $H$ in Run 1 at relative streamwise distances (a) $x / L_{d}=-0.5$ and (b) $x / L_{d}=1$ for relative vertical distances $z / H_{d}=0.05,0.25$ and 0.5 . 
(a)
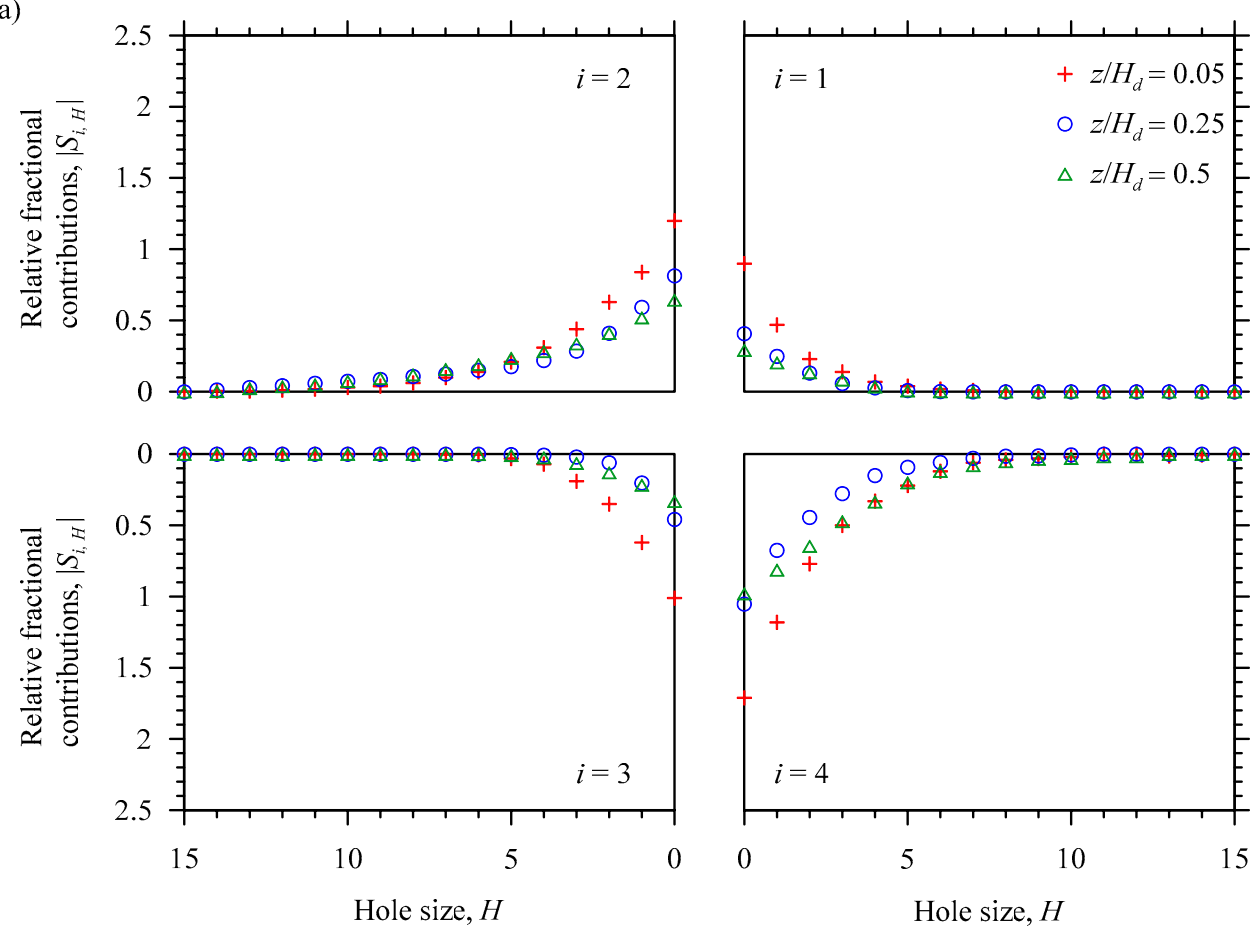

(b)
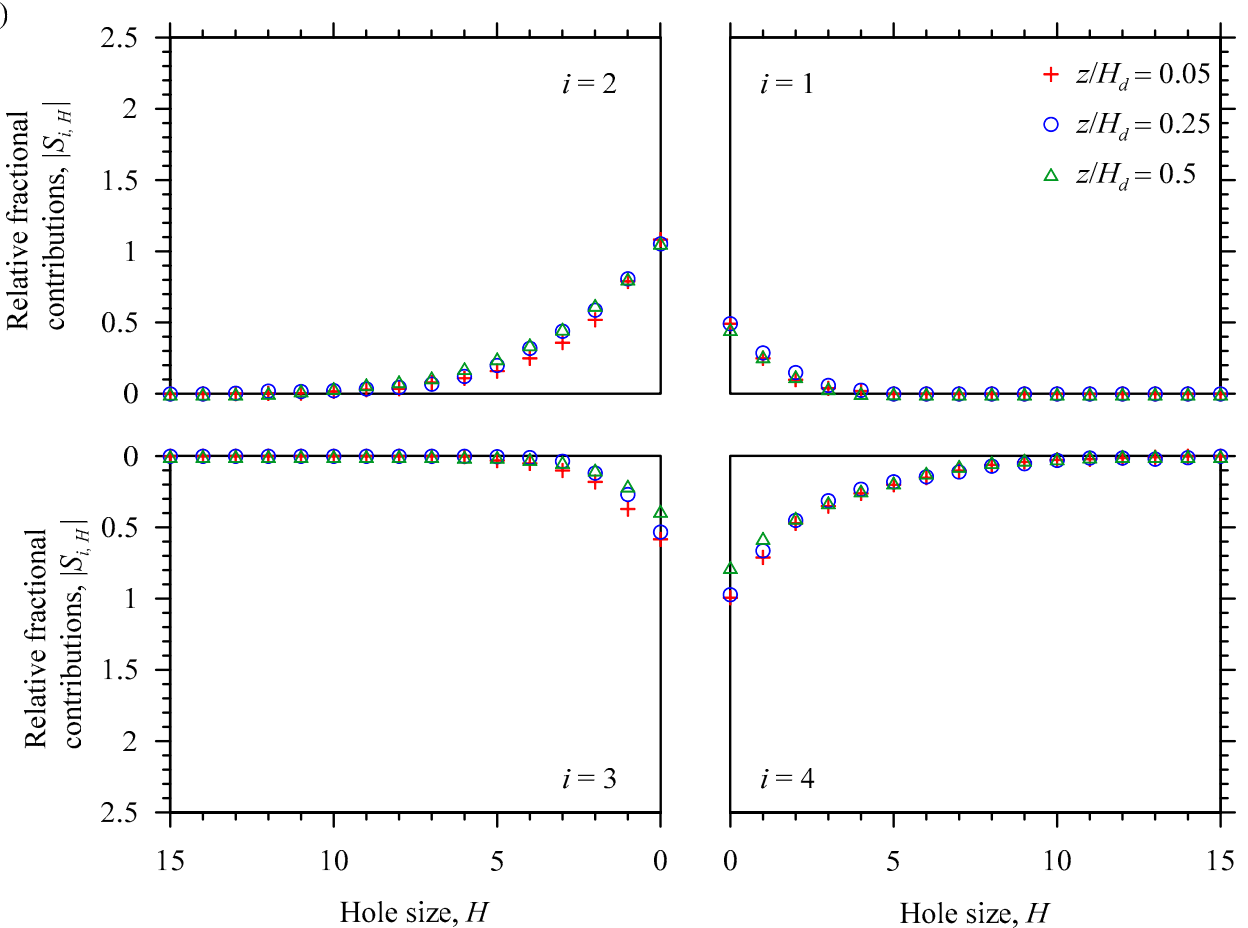

Figure 12. Relative fractional contributions $\left|S_{i, H}\right|$ as a function of hole size $H$ in Run 1 at relative streamwise distances (a) $x / L_{d}=1.7$ and (b) $x / L_{d}=3.3$ for relative vertical distances $z / H_{d}=0.05,0.25$ and 0.5 .

\section{Turbulent Kinetic Energy Budget}

The turbulent kinetic energy budget reads $t_{P}=\varepsilon+t_{D}+p_{D}-v_{D}$, where $t_{P}$ is the turbulent kinetic energy production rate $\left(=-\overline{u^{\prime} w^{\prime}} \partial \bar{u} / \partial z\right), \varepsilon$ is the turbulent kinetic energy dissipation rate, $t_{D}$ is the turbulent kinetic energy diffusion rate $\left(=\partial f_{k w} / \partial z\right), f_{k w}$ is the vertical flux of turbulent kinetic energy, $p_{D}$ is the pressure energy diffusion rate $\left[=\rho^{-1} \partial\left(\overline{p^{\prime} w^{\prime}}\right) / \partial z\right], p^{\prime}$ is the pressure fluctuations, $v_{D}$ is the viscous diffusion rate $\left(=v \partial^{2} k / \partial z^{2}\right)$ and $k$ is the turbulent kinetic energy. In an open channel flow, the $v_{D}$ 
is insignificant compared to other components of the turbulent kinetic energy budget. In this study, Kolmogorov second hypothesis was applied to determine the $\varepsilon$ from the velocity power spectra [28]. The $t_{P}$ and $t_{D}$ were determined from the experimental data, whereas the $p_{D}$ was obtained from the relationship $p_{D}=t_{P}-\varepsilon-t_{D}$. In nondimensional form, the set of variables $\left(t_{P}, \varepsilon, t_{D}, p_{D}\right)$ is expressed as $\left(T_{P}, E_{D}, T_{D}, P_{D}\right)=\left(t_{P}, \varepsilon, t_{D}, p_{D}\right) \times\left(H_{d} / u_{*}^{3}\right)$.

Figure 13 illustrates the vertical profiles of nondimensional components of the turbulent kinetic energy budget at various relative streamwise distances $x / L_{d}$ in Run 1 . Upstream of the dune $\left(x / L_{d}=-0.5\right)$, all the components of the turbulent kinetic energy budget, in the near-bed flow zone, are positive with a sequence of magnitude $T_{P}>E_{D}>P_{D}>T_{D}$ and then, they reduce with an increase in relative vertical distance $z / H_{d}$. Above the dune crest $\left(z / H_{d}>1\right)$, they are quite small. Downstream of the dune $\left(x / L_{d}=1\right.$ to 2.1), the peaks of $T_{P}, E_{D}, P_{D}$ and $T_{D}$ are found to appear at the crest. In the near-bed flow zone, the $T_{P}$ and $E_{D}$ are positive, whereas the $P_{D}$ and $T_{D}$ are negative for $x / L_{d}=1$ to 2.1. Downstream of the dune, the absolute values of $T_{P}, E_{D}, P_{D}$ and $T_{D}$ decrease with an increase in $x / L_{d}$. In particular, at $x / L_{d}=3.3$, the $T_{P}, E_{D}, P_{D}$ and $T_{D}$ profiles are almost similar to those of the undisturbed upstream flow at $x / L_{d}=-0.5$.
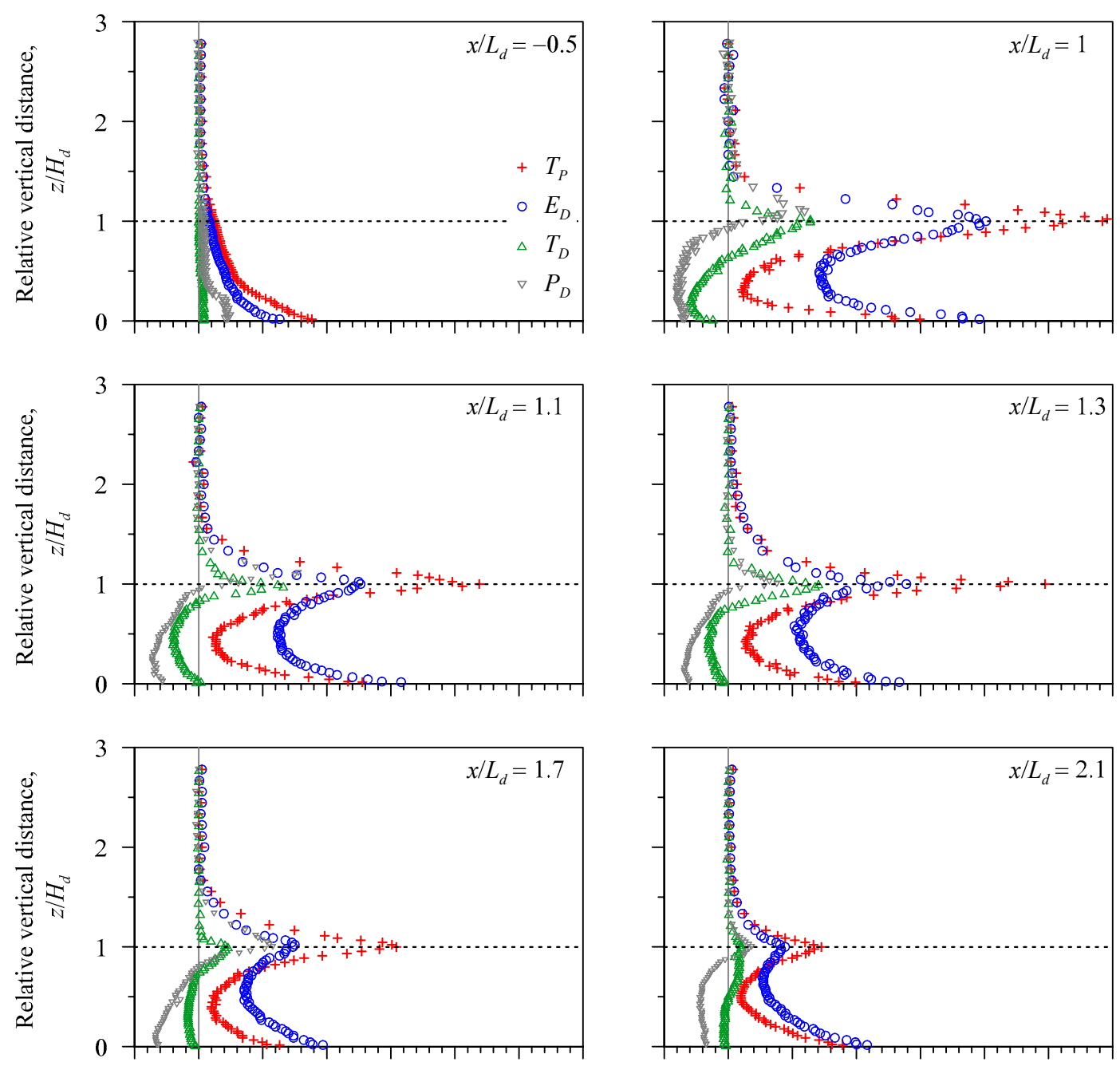

Figure 13. Cont. 

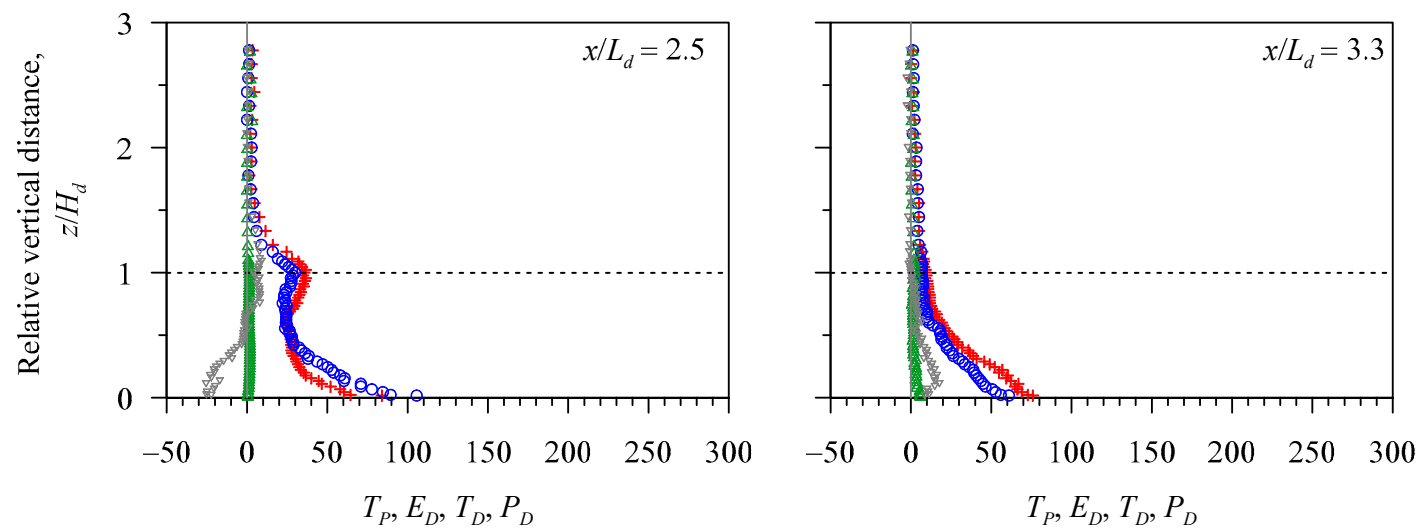

Figure 13. Vertical profiles of the nondimensional components of turbulent kinetic energy budget $T_{P}$, $E_{D}, T_{D}$ and $P_{D}$ at various relative streamwise distances $x / L_{d}$ in Run 1.

\section{Reynolds Stress Anisotropy}

An isotropic turbulence refers to an idealized condition, where the velocity fluctuations at a specific point remain invariant to the rotation of axes. In a lucid way, this condition indicates that the Reynolds normal stresses are identical $\left(\sigma_{x}=\sigma_{y}=\sigma_{z}\right)$, where $\left(\sigma_{x}, \sigma_{y}, \sigma_{z}\right)=\left(\overline{u^{\prime} u^{\prime}}, \overline{v^{\prime} v^{\prime}}, \overline{w^{\prime} w^{\prime}}\right)$. By contrast, in an anisotropic turbulence, the Reynolds normal stresses are dissimilar, because the velocity fluctuations $u^{\prime}{ }_{i}$ $\left[=\left(u^{\prime}, v^{\prime}, w^{\prime}\right)\right.$ for $\left.i=(1,2,3)\right]$ are directionally preferred.

The Reynolds stress anisotropy tensor $b_{i j}$ is expressed as $b_{i j}=\overline{u^{\prime}{ }_{i} u^{\prime}} /(2 k)-\delta_{i j} / 3$, where $\delta_{i j}$ is the Kronecker delta function $\left[\delta_{i j}(i=j)=1\right.$ and $\left.\delta_{i j}(i \neq j)=0\right]$. To ascertain the degree and the nature of anisotropy, the second and third principal invariants, $I_{2}\left(=-b_{i j} b_{i j} / 2\right)$ and $I_{3}\left(=b_{i j} b_{j k} b_{k i} / 3\right)$, respectively, are introduced. The Reynolds stress anisotropy is determined by plotting $-I_{2}$ as a function of $I_{3}$, called the anisotropy invariant map (AIM). In an AIM, the possible turbulence states are confined to a triangle, called the Lumley triangle (Figure 14). The left-curved and the right-curved boundaries of the Lumley triangle, given by $I_{3}= \pm 2\left(-I_{2} / 3\right)^{3 / 2}$, are symmetric about the plane-strain limit $\left(I_{3}=0\right)$. In addition, the top-linear boundary of the Lumley triangle obeys $I_{3}=-\left(9 I_{2}+1\right) / 27$. Dey et al. [29] envisioned the Reynolds stress anisotropy from the perspective of the shape of ellipsoid formed by the Reynolds normal stresses $\left(\sigma_{x}, \sigma_{y}, \sigma_{z}\right)$ in $(x, y, z)$. In an isotropic turbulence $\left(\sigma_{x}=\sigma_{y}=\sigma_{z}\right)$, the stress ellipsoid becomes a sphere (Figure 14). On the left-curved boundary, called the axisymmetric contraction limit, one component of Reynolds normal stress is smaller than the other two equal components $\left(\sigma_{x}=\sigma_{y}>\sigma_{z}\right)$, forming the stress ellipsoid an oblate spheroid. On the left vertex, called the two-component axisymmetric limit, one component of Reynolds normal stress disappears $\left(\sigma_{x}=\sigma_{y}\right.$ and $\left.\sigma_{z}=0\right)$ to make the stress ellipsoid a circular disc (Figure 14). On the right-curved boundary, called the axisymmetric expansion limit, one component of Reynolds normal stress is larger than the other two equal components $\left(\sigma_{x}=\sigma_{y}<\sigma_{z}\right)$, making the stress ellipsoid a prolate spheroid (Figure 14). Further, on the top-linear boundary, called the two-component limit, one component of Reynolds normal stress is larger than the other component together with a third vanishing component $\left(\sigma_{x}>\sigma_{y}\right.$ and $\left.\sigma_{z}=0\right)$, producing the stress ellipsoid an elliptical disk. The point of intersecting of the plain-strain limit and the two-component limit is called the two-component plain-strain limit. Moreover, on the right vertex of the Lumley triangle, called the one-component limit $\left[\left(\sigma_{x}>0, \sigma_{y}=\sigma_{z}=0\right)\right.$ or $\left.\left(\sigma_{x}=\sigma_{y}=0, \sigma_{z}>0\right)\right]$, only one component of Reynolds normal stress sustains to make the stress ellipsoid a straight line (Figure 14). 


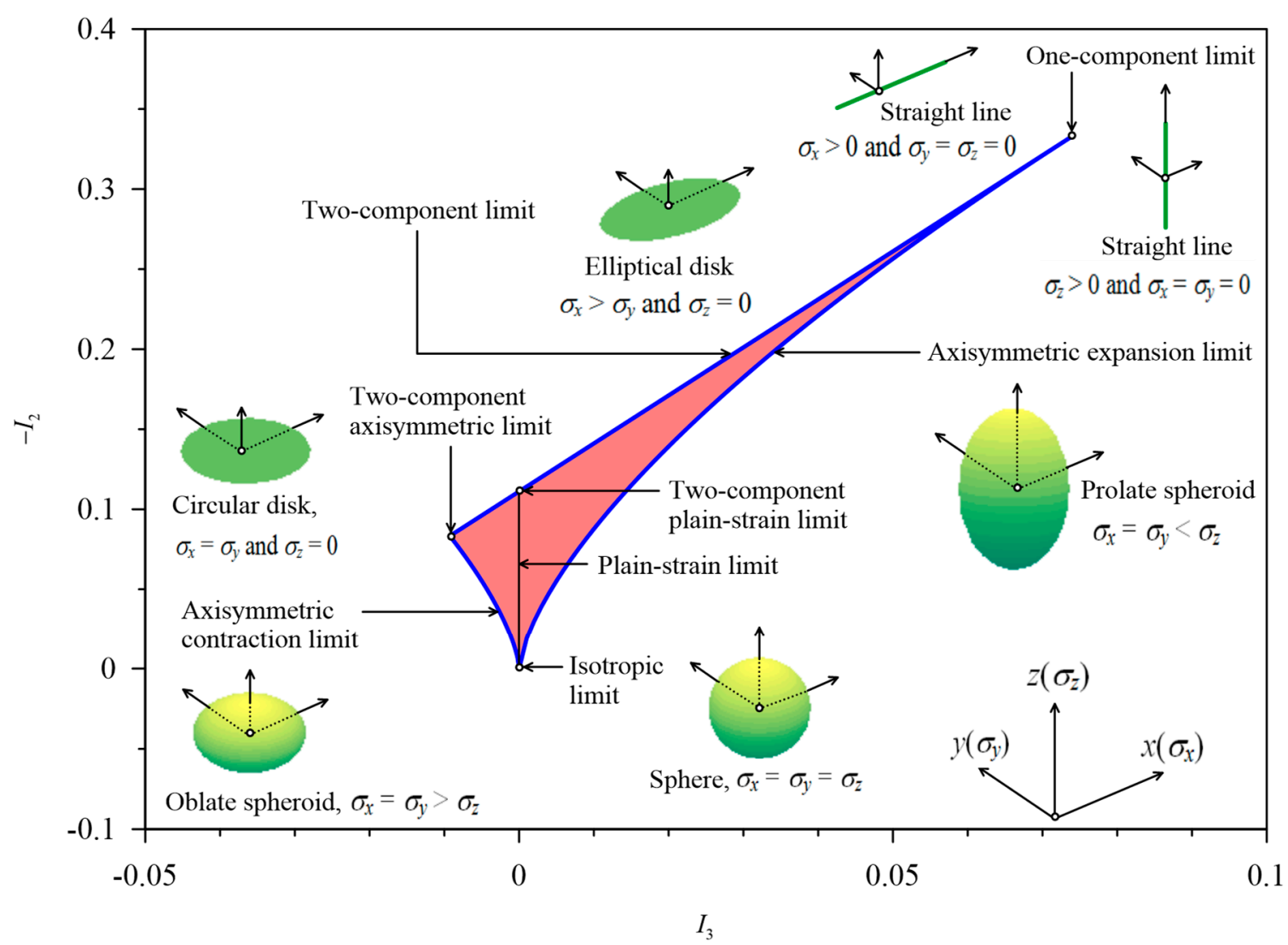

Figure 14. Conceptual representation of Reynolds stress anisotropy.

Figure 15 shows the data plots of $-I_{2}$ versus $I_{3}$, confined to the AIM boundaries, at various relative streamwise distances $x / L_{d}$ in Runs 1 and 2. Upstream of the dune $\left(x / L_{d}=-0.5\right)$, the data plots initiate from the near left vertex, moving toward the bottom cusp, and then, with an increase in vertical distance, they cross the plain-strain limit to shift toward the right-curved boundary. The trends of the data plots for both Runs 1 and 2 are almost monotonic. The AIM of the upstream indicates that as the vertical distance increases, the turbulence anisotropy tends to reduce to a quasi-three-dimensional isotropy. Immediate downstream of the dune, the data plots tend to create a stretched loop inclined to the left-curved boundary. However, below the dune crest $\left(z / H_{d}<1\right)$, the data plots in the near-bed flow zone initiate from the plain-strain limit and with an increase in vertical distance up to the crest, they shift toward the left vertex following the left-curved boundary. This suggests that the turbulence anisotropy has an affinity to a two-dimensional isotropy. Above the crest, the data plots turn toward the right and as the vertical distance increases further, they move toward the bottom cusp following the left-curved boundary. This demonstrates that the turbulence anisotropy tends to reduce to a quasi-three-dimensional isotropy. Further downstream $\left(x / L_{d}=1.7\right)$, the size of the loop created by the data plots reduces forming a tail, and the loop disappears at $x / L_{d}=3.3$, signifying a recovery of the undisturbed upstream trend. It therefore appears that that below the crest, the turbulence has an affinity to a two-dimensional isotropy, whereas above the crest, a quasi-three-dimensional isotropy prevails.

From the perspective of the shape of stress ellipsoid, Figure 15 shows that below the dune crest, an oblate spheroid axisymmetric turbulence is predominant in the wall-wake flow. The line of plain-strain limit $\left(I_{3}=0\right)$ is touched by the curve through the data plots in the near-bed flow zone. This reveals that the axisymmetric contraction to the oblate spheroid enhances as the vertical distance increases up to the crest. However, the axisymmetric contraction to oblate spheroid lessens with a further increase in vertical distance above the crest. 

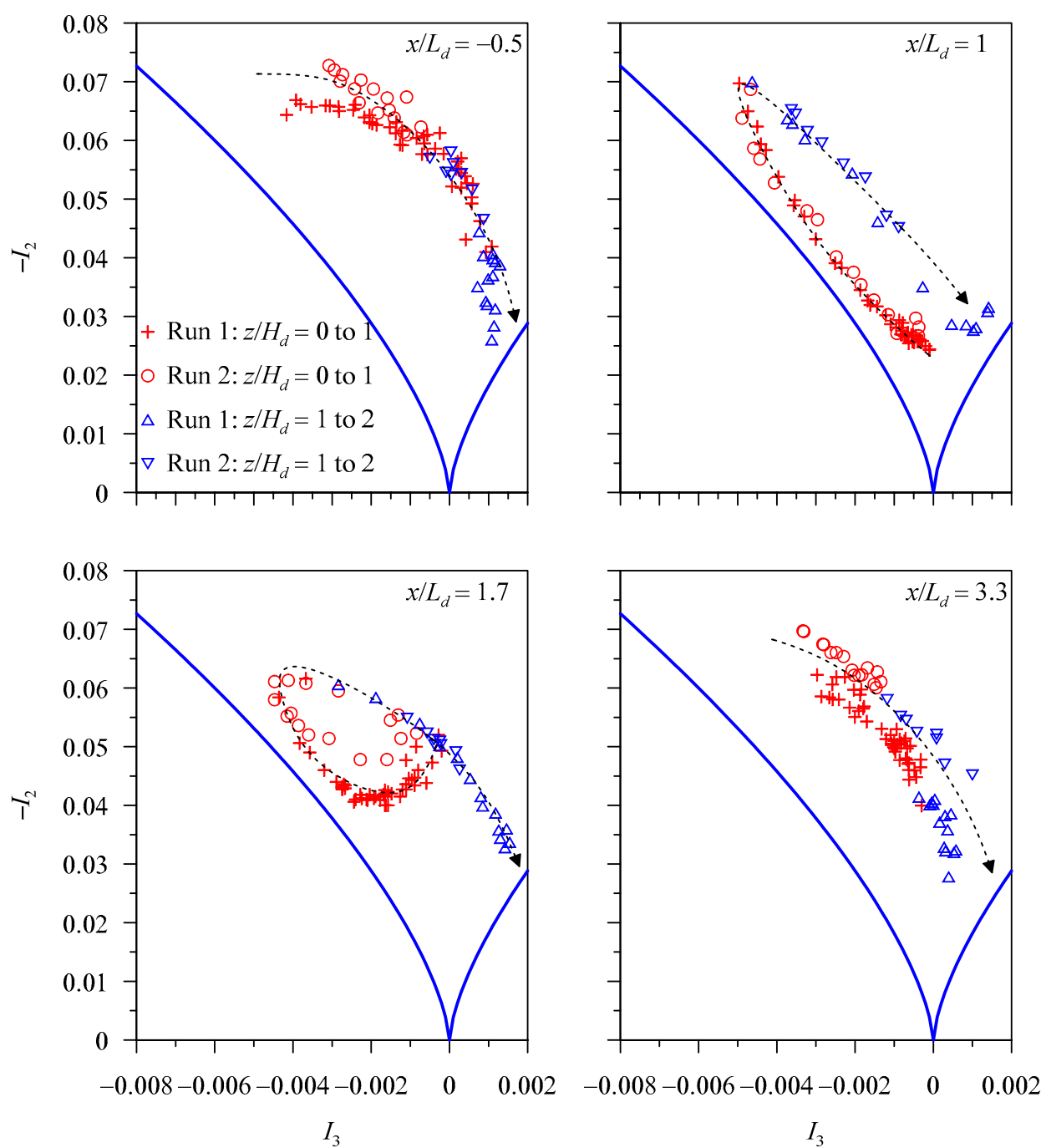

Figure 15. AIMs at various relative streamwise distances $x / L_{d}$ in Runs 1 and 2 .

\section{Conclusions}

This study puts into focus the turbulence in wall-wake flow downstream of an isolated dunal bedform. The vertical profiles of streamwise flow velocity reveal that the near-wake flow zone extends up to 1.7 times the dune length, whereas the streamwise flow velocity profile follows the undisturbed upstream velocity profile beyond 3.3 times the dune length. The Reynolds shear stress in the wall-wake flow is affected by the dune up to a vertical distance of 1.75 times the dune height and a streamwise distance of 2.5 times the dune length. The third-order moment of velocity fluctuations reveal that downstream of the dune, a streamwise acceleration having a downward flux prevails below the dune crest, whereas a streamwise deceleration having an upward flux persists above the crest. Below the crest, the sweeps are found to be the predominant events, whereas above the crest, the ejections are the major events. The components of the turbulent kinetic energy budget reveal an amplification of the magnitudes of the turbulent parameters, which attain their maximum peaks at the crest. The anisotropy invariant maps show that the data plots in the wall-wake flow start from the plain-strain limit in the near-bed flow zone, shifting toward the left vertex of the Lumley triangle up to the crest to show an affinity to a two-dimensional isotropy. Above the crest, the data plots show an affinity to a quasi-three-dimensional isotropy.

In essence, this study advances the current understanding of flow and turbulence characteristics in wall-wake flow downstream of an isolated dunal bedform. The experimental results provide guidance 
to numerical simulations of wall-wake flow. In addition, this study may be helpful, at least qualitatively, to simulate the mobile-bed flow downstream of a dunal bedform.

Author Contributions: Conceptualization, S.S. and S.D; data curation, S.S.; formal analysis, S.S., S.Z.A. and S.D; funding acquisition, S.S.; investigation, S.S., S.Z.A. and S.D; methodology, S.S. and S.D; resources, S.S., S.Z.A. and S.D; writing — original draft, S.S., S.Z.A. and S.D; writing—review and editing, S.S., S.Z.A. and S.D; supervision, S.D.

Funding: This research was funded by Indian Statistical Institute, Kolkata.

Acknowledgments: The third author (S.D) acknowledges the JC Bose fellowship project (project code: JBD) to coordinate this research program.

Conflicts of Interest: The authors declare no conflict of interest.

\section{References}

1. ASCE Task Committee. Flow and transport over dunes. J. Hydraul. Eng. 2002, 128, 726-728. [CrossRef]

2. McLean, S.R.; Smith, J.D. A model for flow over two-dimensional bed forms. J. Hydraul. Eng. 1986, 112, 300-317. [CrossRef]

3. Nelson, J.M.; Smith, J.D. Mechanics of flow over ripples and dunes. J. Geophys. Res. Oceans 1989, 94, 8146-8162. [CrossRef]

4. Maddux, T.B.; Nelson, J.M.; McLean, S.R. Turbulent flow over three-dimensional dunes: 1. Free surface and flow response. J. Geophys. Res. Earth Surf. 2003, 108, 6009. [CrossRef]

5. Maddux, T.B.; McLean, S.R.; Nelson, J.M. Turbulent flow over three-dimensional dunes: 2. Fluid and bed stresses. J. Geophys. Res. Earth Surf. 2003, 108, 6010. [CrossRef]

6. Sukhodolov, A.N.; Fedele, J.J.; Rhoads, B.L. Structure of flow over alluvial bedforms: An experiment on linking field and laboratory methods. Earth Surf. Proc. Landf. 2006, 31, 1292-1310. [CrossRef]

7. Best, J.L. Kinematics, topology and significance of dune-related macroturbulence: Some observations from the laboratory and field. In Fluvial Sedimentology VII; Blum, M.D., Marriott, S.B., Leclair, S.F., Eds.; Special Publication of International Association of Sedimentologists, Wiley-Blackwell (an imprint of John Wiley \& Sons Ltd): Hoboken, NJ, USA, 2005; pp. 41-60.

8. Schlichting, H. Boundary Layer Theory; McGraw-Hill: New York, NY, USA, 1979.

9. Balachandar, R.; Ramachandran, S.; Tachie, M.F. Characteristics of shallow turbulent near wakes at low Reynolds numbers. J. Fluids Eng. 2000, 122, 302-308. [CrossRef]

10. Tachie, M.F.; Balachandar, R. Shallow wakes generated on smooth and rough surfaces. Exp. Fluids 2001, 30, 467-474. [CrossRef]

11. Shamloo, H.; Rajaratnam, N.; Katopodis, C. Hydraulics of simple habitat structures. J. Hydraul. Res. 2001, 39, 351-366. [CrossRef]

12. Dey, S.; Sarkar, S.; Bose, S.K.; Tait, S.; Castro-Orgaz, O. Wall-wake flows downstream of a sphere placed on a plane rough wall. J. Hydraul. Eng. 2011, 137, 1173-1189. [CrossRef]

13. Sarkar, S.; Dey, S. Turbulent length scales and anisotropy downstream of a wall mounted sphere. J. Hydraul. Res. 2015, 53, 649-658. [CrossRef]

14. Kahraman, A.; Sahin, B.; Rockwell, D. Control of vortex formation from a vertical cylinder in shallow water: Effect of localized roughness elements. Exp. Fluids 2002, 33, 54-65. [CrossRef]

15. Akilli, H.; Rockwell, D. Vortex formation from a cylinder in shallow water. Phys. Fluids 2002, 14, $2957-2967$. [CrossRef]

16. Ozgoren, M. Flow structure in the downstream of square and circular cylinders. Flow Meas. Instrum. 2006, 17, 225-235. [CrossRef]

17. Ozturk, N.A.; Akkoca, A.; Sahin, B. Flow details of a circular cylinder mounted on a flat plate. J. Hydraul. Res. 2008, 46, 344-355. [CrossRef]

18. Sadeque, M.A.F.; Rajaratnam, N.; Loewen, M.R. Shallow turbulent wakes behind bed-mounted cylinders in open channels. J. Hydraul. Res. 2009, 47, 727-743. [CrossRef]

19. Dey, S.; Swargiary, D.; Sarkar, S.; Fang, H.; Gaudio, R. Self-similarity in turbulent wall-wake flow downstream of a wall-mounted vertical cylinder. J. Hydraul. Eng. 2018, 144, 04018023. [CrossRef] 
20. Dey, S.; Swargiary, D.; Sarkar, S.; Fang, H.; Gaudio, R. Turbulence features in a wall-wake flow downstream of a wall-mounted vertical cylinder. Eur. J. Mech. B Fluids 2018, 69, 46-61. [CrossRef]

21. Dey, S.; Lodh, R.; Sarkar, S. Turbulence characteristics in wall-wake flows downstream of wall-mounted and near-wall horizontal cylinders. Environ. Fluid Mech. 2018, 18, 891-921. [CrossRef]

22. Lacey, R.W.J.; Roy, A.G. Fine-scale characterization of the turbulent shear layer of an instream pebble cluster. J. Hydraul. Eng. 2008, 134, 925-936. [CrossRef]

23. Sarkar, S.; Dey, S. Turbulence in wall-wake flow downstream of an isolated dune. In Proceedings of the 38th International School of Hydraulics, Łack, Poland, 21-24 May 2019.

24. Dey, S.; Sarkar, S. Turbulent length scales and Reynolds stress anisotropy in wall-wake flow downstream of an isolated dunal bedform. In Proceedings of the 38th International School of Hydraulics, Łack, Poland, 21-24 May 2019.

25. Goring, D.G.; Nikora, V.I. Despiking acoustic Doppler velocimeter data. J. Hydraul. Eng. 2002, 128, 117-126. [CrossRef]

26. Gad-El-Hak, M.; Bandyopadhyay, P.R. Reynolds number effects in wall-bounded turbulent flows. Appl. Mech. Rev. 1994, 47, 307-365. [CrossRef]

27. Lu, S.S.; Willmarth, W.W. Measurements of the structure of the Reynolds stress in a turbulent boundary layer. J. Fluid Mech. 1973, 60, 481-511. [CrossRef]

28. Dey, S. Fluvial Hydrodynamics: Hydrodynamic and Sediment. Transport. Phenomena; Springer: Berlin, Germany, 2014.

29. Dey, S.; Ravi Kishore, G.; Castro-Orgaz, O.; Ali, S.Z. Turbulent length scales and anisotropy in submerged turbulent plane offset jets. J. Hydraul. Eng. 2019, 145, 04018085. [CrossRef]

(C) 2019 by the authors. Licensee MDPI, Basel, Switzerland. This article is an open access article distributed under the terms and conditions of the Creative Commons Attribution (CC BY) license (http://creativecommons.org/licenses/by/4.0/). 